\title{
Facility assessment report: Introducing pay-for-performance (P4P) approach to increase utilization of maternal, newborn, and child health services in Bangladesh
}

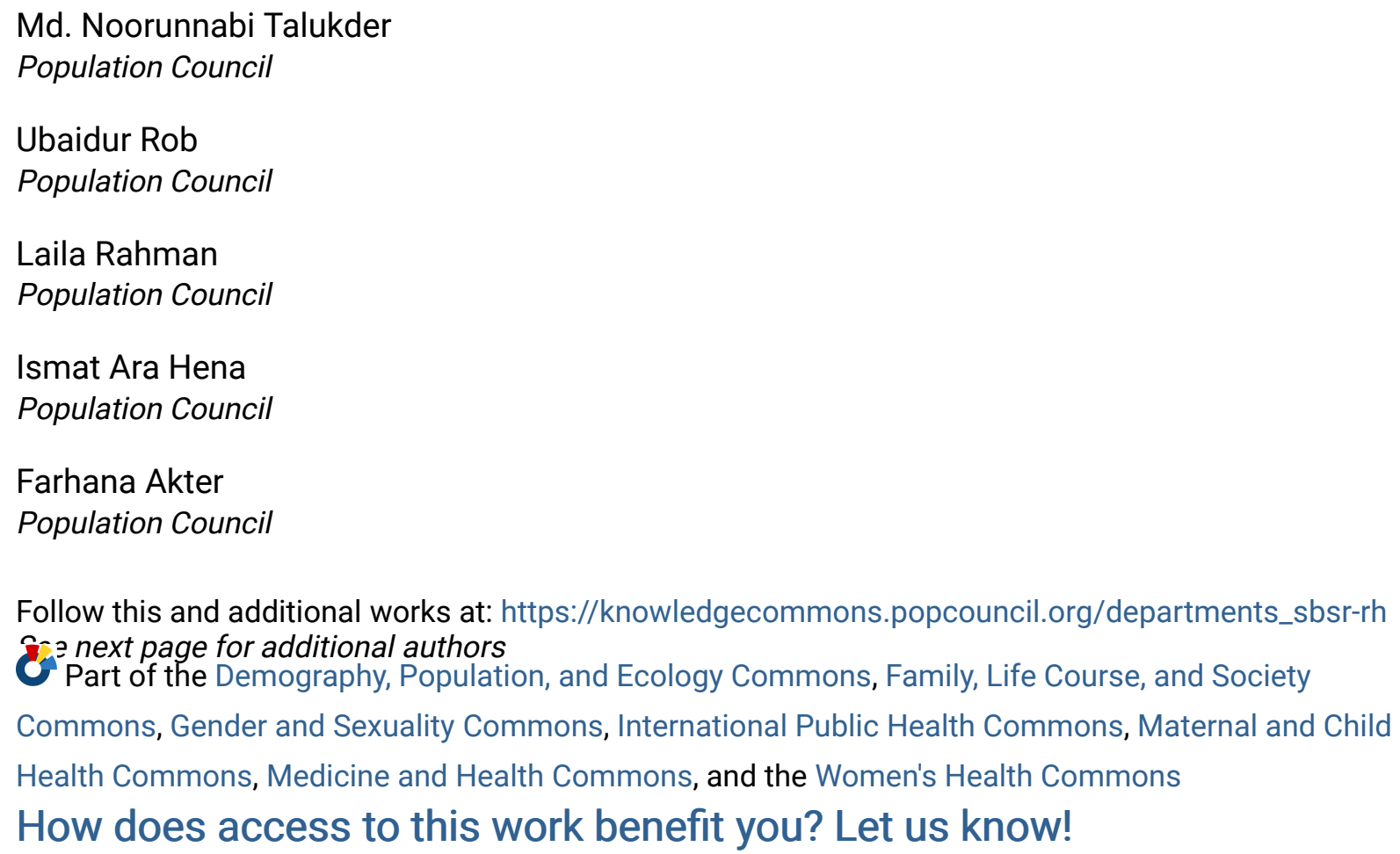

\section{Recommended Citation}

Talukder, Md. Noorunnabi, Ubaidur Rob, Laila Rahman, Ismat Ara Hena, Farhana Akter, Mohammad Ataur Rahman, Md. Julkarnayeen, Md. Akteruzzaman, Md. Sohel Rana, and Ripa Ali. 2010. "Facility assessment report: Introducing pay-for-performance (P4P) approach to increase utilization of maternal, newborn, and child health services in Bangladesh." Dhaka: Population Council. 


\section{Authors}

Md. Noorunnabi Talukder, Ubaidur Rob, Laila Rahman, Ismat Ara Hena, Farhana Akter, Mohammad Ataur Rahman, Md. Julkarnayeen, Md. Akteruzzaman, Md. Sohel Rana, and Ripa Ali 


\section{Facility Assessment Report}

Introducing Pay-for-Performance (P4P) Approach to Increase Utilization of Maternal, Newborn and Child Health Services in Bangladesh

\section{Population Council, Bangladesh}

September 2010

5. Asiralian Genernent unicef(?)
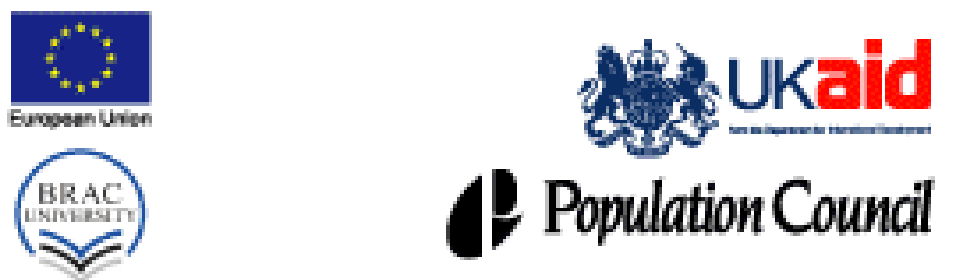

(1) Population Counal 


\section{Facility Assessment Report}

\section{Introducing Pay-For-Performance (P4P) Approach to}

Increase Utilization of Maternal, Newborn and Child Health Services in Bangladesh

Md. Noorunnabi Talukder

Population Council

Ubaidur Rob

Population Council

Laila Rahman

Population Council

Ismat Ara Hena

Population Council

Farhana Akter

Population Council

Mohammad Ataur Rahman

Population Council

Md. Julkarnayeen

Population Council

Md. Akteruzzaman

James P. Grant School of Public Health, BRAC University

Md. Shohel Rana

James P. Grant School of Public Health, BRAC University

Ripa Ali

Population Council

September 2010

This publication is made possible through the financial support of UNICEF/Bangladesh. The opinions expressed herein are those of the authors and do not reflect the views of the Population Council and UNICEF/Bangladesh. 
Suggested citation:

Talukder, Md. Noorunnabi, Ubaidur Rob, Laila Rahaman, Ismat Ara Hena, Farhana Akter, Mohammad Ataur Rahaman, Md. Julkarnayeen, Md. Akteruzzaman, Md. Sohel Rana, and Ripa Ali. 2010 "Facility assessment report on introducing pay-for-performance (P4P) approach to increase utilization of maternal, newborn and child bealtb services in Bangladesh." Dhaka, Bangladesh: Population Council. 


\section{Acknowledgements}

Population Council would like to express sincere gratitude to Dr. A.B.M. Jahangir Alam, DirectorPrimary Health Care and Line Director-Essential Service Delivery, Directorate General of Health Services (DGHS) for his leadership, interest, guidance, collaboration and technical support for initiating and implementing the P4P pilot project. We are deeply indebted to Dr. Kazi Md. Habibur Rahman, Program Manager, Reproductive Health, DGHS for his guidance, insights and continuous support in initiating and implementing the project activities smoothly. We are thankful to Dr. Azizul Alim, Deputy Program Manager, EOC, Reproductive Health, DGHS and Dr. Akhtar Jahan, Deputy Program Manager, $\mathrm{MNH}$, Reproductive Health for their expert opinion and collaboration in carrying out the facility assessment study.

The Council expresses its heartfelt gratitude to UNICEF/Bangladesh for their interest, collaboration and financial contribution in carrying out the P4P project. We sincerely thank Drs. Lubana Ahmed, Monira Parveen, Riad Mahmud and Khairul Islam of UNICEF/Bangladesh for their opinion, insights and support at every step of the facility assessment study. The cooperation of Dr. Rama Das, District Officer-MNH, Jamalpur, UNICEF/Bangladesh is specially acknowledged.

We gratefully acknowledge the support, commitment and technical assistance of our implementing partner: James P. Grant School of Public Health, BRAC University. We express our sincere thanks to the project partners: BRAC Health Program in Gaibandha and Kurigram; and CARE in Jamalpur.

We are grateful to the managers and service providers of the health facilities who participated in the assessment. We sincerely thank Civil Surgeons, Consultants in Gyne/Obs, Pediatrics and Anesthesiology, and Resident Medical Officers of Gaibandha, Kurigram, Jamalpur and Thakurgaon District Hospital for their time and continued support during the study. Similarly, thanks are due to Upazila Health and Family Planning Officers, Resident Medical Officers and specialist doctors of Sundargonj, Fulchari and Shaghata Upazila Health Complexes in Gaibandha; Nageswari, Bhurungamari and Chilmary Upazila Health Complexes in Kurigram; Islampur, Melandah and Bakshiganj Upazila Health Complexes in Jamalpur; and Baliadangi, Pirganj and Ranishankoil Upazila Health Complexes in Thakurgaon. We are also grateful to other staff at those facilities, particularly Upazila Family Planning Officer, nurses, and statistician. Deputy Directors of Family Planning in Gaibandha, Kurigram, Jamalpur and Thakurgaon deserve special thanks.

We are indebted to Mr. A.K.M. Zafar Ullah Khan, Adviser to Population Council/Bangladesh for his continued technical assistance and for reviewing the draft version of the report and providing useful comments.

Finally, we are thankful to Population Council colleagues for technical, administrative and logistical support. 


\section{Abbreviations}

$\begin{array}{ll}\text { BEmONC } & \text { Basic Emergency Obstetric and Neonatal Care } \\ \text { CEmONC } & \text { Comprehensive Emergency Obstetric and Neonatal Care } \\ \text { DDFP } & \text { Deputy Director Family Planning } \\ \text { DGHS } & \text { Directorate General of Health Services } \\ \text { EOC } & \text { Essential Obstetric Care } \\ \text { EmONC } & \text { Emergency Obstetric and Neonatal Care } \\ \text { GOB } & \text { Government of Bangladesh } \\ \text { HFA } & \text { Health Facility Assessment } \\ \text { IMCI } & \text { Integrated Management of Childhood Illnesses } \\ \text { MO-MCHFP } & \text { Medical Officer-Maternal and Child Health and Family Planning } \\ \text { MIS } & \text { Management Information System } \\ \text { MNH } & \text { Maternal and Newborn Health } \\ \text { MNCH } & \text { Maternal, Newborn and Child Health } \\ \text { MOHFW } & \text { Ministry of Health and Family Welfare } \\ \text { OT } & \text { Operation Theater } \\ \text { P4P } & \text { Pay-for-Performance } \\ \text { QAG } & \text { Quality Assurance Group } \\ \text { RMO } & \text { Resident Medical Officer } \\ \text { UHFPO } & \text { Upazila Health and Family Planning Officer } \\ \text { UFPO } & \text { Upazila Family Planning Officer } \\ \text { UHC } & \text { Upazila Health Complex } \\ \text { UNICEF } & \text { United Nations Children's Fund }\end{array}$




\section{Executive Summary}

Under the leadership of Directorate General of Health Services (DGHS), the Population Council in collaboration with James P. Grant School of Public Health, BRAC University and with support from UNICEF is testing an innovative service delivery model to provide financial incentives to the institution as a way to enhance their performance on maternal, newborn and child health $(\mathrm{MNCH})$ services in Gaibandha, Kurigram and Jamalpur districts as part of GOB-UNICEF's ongoing MNCH/MNH projects. This project (known as P4P project) is implemented in 12 facilities in 3 districts (one District Hospital and three Upazila Health Complexes from each district). Facilities in Gaibandha, Kurigram, Jamalpur are exposed to the program interventions. Similarly, 4 facilities from Thakurgaon district have been included in the $\mathrm{P} 4 \mathrm{P}$ project, which are not exposed to program interventions. Facilities in Thakurgaon district are the control/comparison sites.

The first and foremost prerequisite for implementing P4P approach is that health facilities remain functional with necessary human resources, infrastructure, and logistics and supplies. To this end, all 16 study facilities were assessed to examine their present condition and identify the gaps in the service delivery in terms of physical and human assets at the preparatory phase of the strategic planning of the P4P project. Among 16 facilities, 8 facilities provide comprehensive emergency obstetric and newborn care (CEmONC) services; and the remaining 8 facilities provide basic emergency obstetric and newborn care (BEmONC) services. CEmONC facilities that were assessed are: Gaibandha District Hospital; Kurigram District Hospital; Jamalpur District Hospital; Thakurgaon District Hospital; Sundargonj Upazila Health Complex, Gaibandha; Nageswari Upazila Health Complex, Kurigram; Islampur Upazila Health Complex, Jamalpur; and Baliadangi Upazila Health Complex, Thakurgaon. Facilities that were assessed for service readiness of basic emergency obstetric care are: Fulchari Upazila Health Complex, Gaibandha; Shaghata Upazila Health Complex, Gaibandha; Bhurungamari Upazila Health Complex, Kurigram; Chilmary Upazila Health Complex, Kurigram; Melandah Upazila Health Complex, Jamalpur; Bakshiganj Upazila Health Complex, Jamalpur; Pirganj Upazila Health Complex, Thakurgaon; and Ranishankoil Upazila Health Complex, Thakurgaon.

The data collection was carried out by researchers of Population Council and James P. Grant School of Public Health, BRAC University. Earlier, the Council developed the draft data collection instrument through review of similar existing instruments and expert opinion, which was shared with DGHS and UNICEF. Based on the comments received from DGHS and UNICEF, data collection instrument was finalized. Data were collected through key informant interviews and observation. Interviews were conducted with Civil Surgeon, Deputy Director-Family Planning, Consultants in Gyne/Obs, Pediatrics and Anesthesiology, Upazila Health and Family Planning Officer, Upazila Family Planning Officer, Resident Medical Officer, doctors, nurses, and statistician. Human resources data were also collected.

A comparative analysis on the availability and condition of physical and human assets across 16 health facilities has been made, which will tell what is actually needed in a facility in terms of inputs and processes. The analysis was done according to the types of facility. Findings of this assessment need to be fed into for improving facility-based performance and service quality.

Information collected on physical infrastructure was analyzed in terms of building, utility, infection prevention, communication and transportation. Regarding facility building, information on availability of female beds, labor rooms, labor beds and neonatal beds were collected. It was found that there was no facility without any female beds. Among all 16 facilities, Bhurungamari Upazila Health Complex, Kurigram did not have a functioning labor room. Shaghata Upazila Health Complex, Gaibandha did not 
have any labor beds. There were neonatal beds at all the District Hospitals while 7 out of 12 Upazila Health Complexes reported having no neonatal beds.

All District Hospitals had generators. However, the generators in Gaibandha and Thakurgaon District Hospitals were not functional. Majority of the Upazila Health Complexes had the generator, which was, however, not in a working condition. None of the Upazila Health Complexes in Jamalpur district had the generator.

All District Hospitals practiced infection prevention through autoclave-sterilization of instruments and provision of separate waste bins for liquids, solid and sharp. Like District Hospital, Upazila Health Complexes in Thakurgaon practiced autoclave-sterilization. None of the Upazila Health Complexes in Gaibandha practiced infection prevention through autoclave-sterilization of instruments. Infection prevention was maintained properly through autoclave-sterilization of instruments at Chilmary and Nageswari Upazila Health Complexes in Kurigram as well as in Islampur Upazila Health Complex in Jamalpur. However, it was not common among the Upazila Health Complexes in all four districts to maintain separate waste bins for liquid, solid and sharp.

Modern communication system with land phone, dedicated mobile phone and computer was available at all facilities. However, not all facilities reported having the internet connections. Ambulance was available at all facilities, but its availability over phone was not reported at all Upazila Health Complexes.

Analysis of information on the availability of doctors at the facilities indicates that Jamlapur was in the best condition in terms of headcount of doctors, while Gaibandha was in the worst condition. On the other hand, all the facilities had most of the required number of nurses. Facilities in Gaibandha were in the best condition in terms of availability of nurses followed by facilities in Jamalpur. There was a clear need for Essential Obstetric Care (EOC) and Integrated Management of Childhood Illnesses (IMCI) training for service providers at all facilities.

Jamalpur District Hospital had all three types of specialist doctors: Consultant-Gyne/Obs, ConsultantAnesthesiology, and medical officer trained in Pediatrics, while Gaibandha District Hospital did not have any of the specialist doctors. Kurigram District Hospital did not have the Consultants in Anesthesiology and Pediatrics. Thakurgaon District Hospital had no Consultant-Pediatrics. Several posts of Emergency Medical Officers and Medical Officers remained vacant at the District Hospitals. The situation at Jamalpur and Kurigram District Hospitals was the best where only 1 out of 11 posts needed to be filled in Jamalpur and 1 out of 8 posts in Kurigram. At Gaibandha District Hospital, 3 out of 10 posts of Emergency Medical Officer and Medical Officer remained vacant. Thakurgaon District Hospital had all 3 Emergency Medical Officers while all 4 positions of Medical Officer were vacant.

Among four CEmONC Upazila Health Complexes, Islampur Upazila Health Complex, Jamalpur had all required specialist doctors. Sundargonj Upazila Health Complex, Gaibandha needed to fill in the vacant post of a Consultant-Pediatrics. Nageswari Upazila Health Complex, Kurigram had no ConsultantAnesthesiology, which is needed to be filled in on priority basis provided the facility offers cesarean section. Human resources situation at Baliadangi Upazila Health Complex, Thakurgaon was not sufficient to offer CEmONC services, because it was lacking Consultant-Gyne/Obs and ConsultantPediatrics. Analysis of information of medical officers at the CEmONC Upazila Health Complexes reveals the unavailability of medical officers at Sundargonj Upazila Health Complex while Islampur, Nageswari and Baliadangi Upazila Health Complexes had the required number of medical officers.

Among 8 BEmONC Upazila Health Complexes, Shaghata Upazila Health Complex, Gaibandha did not have any doctors against the sanctioned posts other than the Upazila Health and Family Planning 
Officer. Human resources situation was unacceptably insufficient at the Fulchari Upazila Health Complex, Gaibandha where only one-third of the doctors were available. Melandah Upazila Health Complex, Jamalpur was the only facility where there was no shortage in the number of doctors against the sanctioned posts. Human resources situation was poor at the Bakshiganj Upazila Health Complex, Jamalpur with reported availability of half of the doctors. Bhurungamari Upazila Health Complex, Kurigram needed to fill in two vacant positions of doctors. Availability of human resources was in the poorest condition at Chilmary Upazila Health Complex, Kurigram with the vacancy of 8 doctors against 12 positions. The headcount of doctors at Pirganj Upazila Health Complex, Thakurgaon indicates the availability of half of the doctors. At Ranishankoil Upazila Health Complex, Thakurgaon only 3 out of 9 doctors were available.

The availability and status of 15 items of equipment, logistics and supplies were systematically assessed. The items include: anesthesia machine; oxygen cylinder; emergency light; vacuum extractor; functioning forceps; delivery set; sucker machine; ambu bag; neo-natal resuscitator; nebulizer solution; weighing machine; blood grouping and cross matching reagents; blood bag; doctor's gown, musk and cap; and gloves. Thakurgaon District Hospital was in the best position regarding the availability and condition of equipment, logistics and supplies. Fourteen out of 15 items were available and in working condition at the facility. Twelve out of 15 items were available and in working condition in both Gaibandha and Kurigram District Hospitals. Among District Hospitals, Jamalpur District Hospital had the fewest number of items, where 9 out of 15 items were available and in working condition.

Comparison of availability of equipment, logistics and supplies across four CEmONC Upazila Health Complexes indicates a good condition at all facilities. Among the four facilities, Baliadangi Upazila Health Complex was in the best condition, which had 14 items of Equipment, logistics and supplies. Thirteen out of 15 items were available and in working condition at Islampur and Nageswari Upazila Health Complexes. Sundargonj Upazila Health Complex had 12 items. Among eight BEmONC Upazila Health Complexes, two facilities were in good condition regarding the availability of equipment, logistics and supplies. Pirganj Upazila Health Complex, Thakurgaon was in the best condition followed by Melandah Upazila Health Complex, Jamalpur.

All facilities reported availability of most of the essential medicines for mother and child. Kurigram District Hospital was found in the best condition regarding the availability of essential medicines for mother and child, followed by Jamalpur District Hospital. Among CEmONC Upazila Health Complexes, Sundargonj Upazila Health Complex, Gaibandha and Baliadangi Upazila Health Complex, Thakurgaon had all the required supplies of essential medicines for mother and child, while Nageswari Upazila Health Complex, Kurigram was in relatively poor condition. Among eight BEmONC Upazila Health Complexes, only Pirganj Upazila Health Complex, Thakurgaon had all the required supplies of essential medicines for mother and child.

This report presents the key findings of the rapid assessment of 16 government health facilities conducted in the preparatory phase of the P4P project. A comprehensive assessment (to be conducted by Consultant doctors) will be followed before incentive-related intervention activities can be initiated. Indicators that are to be used for comprehensive assessment (intended for facility accreditation) will be both technical and detailed.

It has emerged from this assessment report that no facility is in a perfect condition to provide quality $\mathrm{MNCH}$ services as all the facilities are burdened with problems related to human resource, physical infrastructure, equipment, logistics and supplies, and medicines. Before initiating the performance-based incentives, the lacks in physical and human assets identified through the rapid facility assessment and 
facility accreditation must be addressed. Subsequently, the DGHS will be requested to solve the human resource problem. For logistics and equipment, UNICEF will be intimated to take initiatives. Population Council will be responsible for ensuring the regular supply of medicines and consumables. 


\section{Table of Contents}

Acknowledgements $\quad$ iv

Abbreviations $\quad$ V

Executive Summary $\quad$ vi

$\begin{array}{lr}\text { Introduction } & 1\end{array}$

$\begin{array}{lr}\text { Objective } & 1\end{array}$

$\begin{array}{lr}\text { Methodology } & 1\end{array}$

$\begin{array}{ll}\text { Findings } & 3\end{array}$

Gaibandha District $\quad 3$

Kurigram District $\quad 5$

$\begin{array}{ll}\text { Jamalpur District } & 7\end{array}$

$\begin{array}{lr}\text { Thakurgaon District } & 8\end{array}$

$\begin{array}{lr}\text { Discussions and Recommendations } & 11\end{array}$

$\begin{array}{ll}\text { Physical infrastructure } & 11\end{array}$

$\begin{array}{ll}\text { Human resources } & 12\end{array}$

$\begin{array}{ll}\text { Equipment, logistics and supplies } & 14\end{array}$

$\begin{array}{ll}\text { Medicines } & 15\end{array}$

$\begin{array}{lr}\text { Way Forward } & 17\end{array}$

Annexure 1: Facility Assessment Checklist 19

Annexure 2: Physical Infrastructure Data 37

Annexure 3: Health Human Resources Data 41

Annexure 4: Equipment and Supplies Data 45 
xi | P a g e 


\section{INTRODUCTION}

Under the leadership of Directorate General of Health Services (DGHS), Population Council in collaboration with James P. Grant School of Public Health, BRAC University and with support from UNICEF is testing an innovative service delivery model to provide financial incentives to the institution as a way to enhance their performance on maternal, newborn and child health $(\mathrm{MNCH})$ services in Bangladesh as part of GOB-UNICEF's ongoing $\mathrm{MNCH} / \mathrm{MNH}$ projects. This project (known as P4P project) is implemented in four out of eight $\mathrm{MNCH} / \mathrm{MNH}$ districts where UNICEF provides technical assistance to strengthen the public health facilities while BRAC and CARE are engaged in raising awareness and strengthening the capacity of community-based service providers in the project areas.

In Bangladesh, District health system is comprised of a District Hospital and Upazila Health Complexes. The P4P project is implemented in four districts: Gaibandha, Kurigram, Jamalpur, and Thakurgaon. From each district, District Hospital and three Upazila Health Complexes (UHCs) have been selected for the P4P project. Health facilities in Gaibandha, Kurigram, Jamalpur are exposed to the program interventions while facilities in Thakurgaon district are the control sites.

The first and foremost prerequisite for implementing P4P approach is that health facilities remain functional with necessary human resources, infrastructure, and logistics and supplies. To this end, assessment of the facility is necessary before incentive-related intervention activities can be initiated.

\section{OBJECTIVE}

The main objective of the assessment was to know the present condition of the facility regarding infrastructure, human resources, equipment, logistics and medicines and also to identify problems and gaps of the facility in providing quality service so that initiatives can be made to improve service quality.

\section{METHODOLOGY}

Health Facility Assessment (HFA) was conducted at the preparatory phase of the strategic planning of the P4P project with the purpose to have reliable information on available health resources and their conditions. The facility survey was designed to assist program managers to plan improvement of health service delivery system by assessing health facilities whether they meet the standard criteria to provide $\mathrm{MNCH}$ services. It collected detailed information on the availability of human resources, the availability and condition of the physical assets, and physical access. It also covered limited dimensions of the quality of obstetric and newborn care services. HFA serves as a baseline for increasing investment into the facility.

\section{Sampling population}

Data were collected from all 16 facilities, 8 of the facilities provide comprehensive emergency obstetric and newborn care (CEmONC) services; and the remaining 8 facilities provide basic emergency obstetric and newborn care (BEmONC) services. District Hospital provides CEmONC services and there are some Upazila Health Complexes that also offer CEmONC services. CEmONC facilities that were assessed are: Gaibandha District Hospital; Kurigram District Hospital; Jamalpur District Hospital; 
Thakurgaon District Hospital; Sundargonj UHC, Gaibandha; Nageswari UHC, Kurigram; Islampur UHC, Jamalpur; and Baliadangi UHC, Thakurgaon.

The following facilities were assessed for service readiness of basic emergency obstetric care: Fulchari UHC, Gaibandha; Shaghata UHC, Gaibandha; Bhurungamari UHC, Kurigram; Chilmary UHC, Kurigram; Melandah UHC, Jamalpur; Bakshiganj UHC, Jamalpur; Pirganj UHC, Thakurgaon; and Ranishankoil UHC, Thakurgaon.

\section{Data collection}

The data collection was carried out by researchers of Population Council and James P. Grant School of Public Health, BRAC University after necessary orientation had been provided to them. The Council developed the data collection tool. The process of developing the data collection tool included review of similar existing tools and expert opinion. The Council developed the draft tool and shared it with DGHS and UNICEF for review, and later finalized the tool based on the comments received from DGHS and UNICEF.

Data were collected through key informant interviews and observation. Interviews were conducted with Civil Surgeon, Deputy Director-Family Planning, Consultants in Gyne/Obs, Pediatrics and Anesthesiology, Upazila Health and Family Planning Officer, Upazila Family Planning Officer, Resident Medical Officer, doctors, nurses, and statistician. Human resources data were also collected.

Facility assessment measured a set of up to 46 standard indicators of service readiness and quality. These indicators captured information essential for needs assessment and planning investment in the health system. The number of indicators varied by type of facility. The facility assessment resulted in the development of data sets on: (i) physical infrastructure; (ii) health human resources; and (iii) equipment and supplies. 


\section{FINDINGS}

This section provides a summary of the assessment of study facilities in four districts, focusing on important features of physical infrastructure, health human resources, and equipment and supplies. The findings are presented district wise, which will tell what is actually happening at different levels of service delivery in a district in terms of inputs and processes.

\section{A. Gaibandha District}

In Gaibandha district, HFA was conducted in four facilities - District Hospital, Sundargonj, Fulchari and Shaghata Upazila Health Complexes - from 25 to 26 May 2010.

\section{Physical infrastructure}

Information was collected on the building, utility, communication and transportation. It was found that Gaibandha District Hospital allocated two-thirds of its beds as female beds (65 female beds). Approximately, one-third of the total beds were allocated as female beds at the Upazila Health Complexes, where the number of female beds varied a little from 10 to 12. There was the provision of labor beds in three facilities while Shaghata Upazila Health Complex was having no labor beds. There were neonatal beds in three facilities while Sundargonj Upazila Health Complex did not have any.

Labor rooms in all study facilities were found in a good working condition. Labor instruments were autoclaved properly at the facilities. At Gaibandha District Hospital, infection prevention through autoclave was maintained properly in both OT and labor room with separate waste bins for liquid, solid, and sharp. At the Upazila Health Complexes, infection prevention through separate waste bins for liquid, solid, and sharp was not practiced.

None of the facilities reported uninterrupted supply of electricity. District Hospital and Fulchari Upazila Health Complex had generator but non-functioning while remaining two facilities did not have any generator. All facilities had modern communication system with land phone, dedicated mobile phone, and computer with internet connections. Ambulance was available at all facilities, but its availability over phone was reported by District Hospital and Fulchari and Shaghata Upazila Health Complexes. Data were collected and aggregated systematically by different units of services at each facility. Management Information System (MIS) reports were timely prepared and submitted. All facilities maintained computer-based MIS.

All study facilities in Gaibandha had the provision for round-the-clock services, but did not have the necessary staff strength to provide the service smoothly.

\section{Human resources}

Information on the availability of RMO, Consultants in Pediatrics, Gyne/Obs and Anesthesiology, Medical Officers, Emergency Medical Officers (applicable for District Hospital) and Medical OfficerMCH-FP (applicable for UHC) was collected. Analysis of data on human resources does not provide an optimistic scenario. Only one out of the four facilities had almost all medical professionals against the sanctioned post. Information on whether doctors and nurses received Emergency Obstetric Care (EOC) or Integrated Management of Childhood Illnesses (IMCI) training was also gathered.

Gaibandha District Hospital had the RMO in place. But, the facility had no Consultants in Gyne/Obs and Anesthesiology. Moreover, three out of ten posts of Emergency Medical Officer and Medical Officer remained vacant. Among the available doctors in this facility, two were trained on EOC and one 
on IMCI. Unlike doctors, availability of nurses was satisfactory. There were 20 nurses against 23 positions. Among the nurses, two had EOC training but none reported having IMCI training.

Human resources situation was good at Sundargonj Upazila Health Complex, where ConsultantGyne/Obs, Consultant-Pediatrics, and MO-MCHFP were available against the sanctioned post. The post of RMO was vacant and the facility needed to fill in the vacant post of a Consultant-Pediatrics and two medical officers. Among the doctors, there was one EOC-trained doctor in the facility. None of the doctors had IMCI training. The facility reported availability of all nine nurses. Among the nurses, four were EOC-trained while four other nurses were trained on IMCI.

There were no RMO and consultants at Fulchari Upazila Health Complex. The facility had only two doctors, who reported not having EOC or IMCI training. Nurses for all nine positions were available. Among the nurses, one was trained in EOC and three received IMCI training.

Shaghata Upazila Health Complex did not have any doctors against the sanctioned posts other than the UHFPO. On the other hand, the facility reported the availability of all nine nurses. Among them, two were trained on IMCI.

\section{Equipment, logistics and supplies}

The availability and status of 15 items of equipment, logistics and supplies were systematically assessed. Items include: anesthesia machine, oxygen cylinder, emergency light, vacuum extractor, functioning forceps, delivery set, sucker machine, ambu bag, neo-natal resuscitator, nebulizer solution, weighing machine, blood grouping and cross matching reagents, blood bag, doctor's gown, musk and cap, and gloves.

Twelve out of 15 equipment, logistics and supplies were available and in working condition at Gaibandha District Hospital. The facility, however, reported non-availability of vacuum extractor, neo-natal resuscitator and nebulizer solution.

Comparison of availability of equipment, logistics and supplies across three Upazila Health Complexes indicates that Sundargonj Upazila Health Complex matched with the District Hospital in terms of the number of items. Sundargonj Upazila Health Complex reported unavailability of blood bag. Blood grouping and cross matching reagents that were available at the Sundargonj Upazila Health Complex were non-usable.

Eight out of fifteen items were available at Fulchari Upazila Health Complex. The facility needed vacuum extractor, functioning forceps, delivery set, neo-natal resuscitator, nebulizer solution, blood grouping and cross matching reagents, and blood bag. There was an anesthesia machine at the facility, but it was non-functioning.

Shaghata Upazila Health Complex was in the worst condition in terms of the availability of equipment, logistics and supplies. Only seven items were available at the time of assessment. Anesthesia machine, vacuum extractor, functioning forceps, delivery set, neo-natal resuscitator, blood grouping and cross matching reagents, blood bag, and doctor's gown, musk and cup were not available. There was nebulizer solution, but it was non-usable.

Common medicines were available at all four facilities in Gaibandha at the time of assessment. Among these facilities, only Sundargonj Upazila Health Complex had the required supplies of essential medicines for mother and child. Some essential medicines for mother and child, e.g., Oxytocin, Hartman's Solution, Gentamicin, Erythromycin and Folic Acid were not available at the District Hospital. Similarly, 
Oxytocin, Hartman's Solution and Gentamicin were unavailable at Fulchari Upazila Health Complex, and Shaghata Upazila Health Complex reported unavailability of Hartman's Solution, Gentamicin and Erythromycin.

\section{B. Kurigram District}

Kurigram District Hospital, Bhurungamari, Chilmary and Nageswari Upazila Health Complexes were assessed from 18 to 20 July 2010.

\section{Physical infrastructure}

In the 100-bedded Kurigram District Hospital, there were 35 female beds. Across the Upazila Health Complexes, the number of female beds did not vary considerably (14 to 16 beds). All facilities except Bhurungamari Upazila Health Complex had labor room and beds. There were neonatal beds only at the District Hospital and Nageswari Upazila Health Complex out of four facilities.

Condition of labor rooms across the study facilities varied. OT and labor rooms of Kurigram District Hospital were in good working condition. At the OT, infection prevention was maintained properly through autoclave-sterilization of instruments and provision of separate waste bins for liquids, solid and sharp. Labor room of Kurigram District Hospital had a mixed condition with all labor instruments being autoclaved properly but separate waste bins not maintained. Nageswari and Chilmary Upazila Health Complexes had functioning labor rooms and labor beds in the ward, while labor room at Bhurungamari Upazila Health Complex was not functioning. At Negeswari Upazila Health Complex infection prevention was maintained properly in both OT and labor room through autoclave-sterilization of instruments, but separate waste bins for liquid, solid, and sharp were not maintained. At Chilmary Upazila Health Complex, there was no separate waste bins for liquid, solid and sharp.

Only District Hospital reported uninterrupted supply of electricity with a functioning generator. All three Upazila Health Complexes had generators but were found non-functioning. All four facilities had modern communication system with land phone, dedicated mobile phone, and computer. Only Chilmary Upazila Health Complex did not have internet connections. District Hospital and Nageswari Upazila Health Complex maintained computer-based MIS. Ambulance was available in all four facilities but its availability over phone was reported at three facilities: District Hospital, and Bhurungamari and Nageswari Upazila Health Complexes.

There were necessary staff strength and facilities (obstetrician, pediatrician, and anesthesiologist and blood transfusion with screening) only at District Hospital and Nageswari Upazila Health Complex for round-the-clock CEmONC services.

\section{Human resources}

Analysis of information on the availability of RMO, Consultants in Pediatrics, Gyne/Obs and Anesthesia, Medical Officers, Emergency Medical Officers and MO-MCHFP provides a mixed condition in terms of headcounts of those service providers. Nageswari Upazila Health Complex was found in the best condition followed by Kurigram District Hospital.

There was one Consultant-Gyne/Obs against two posts at Kurigram District Hospital. Moreover, the facility had no Consultant-Anesthesiology and Consultant-Pediatrics against the sanctioned posts at the time of assessment. There were three Medical Officers against four posts. Among doctors, one medical officer received EOC training but no medical officer had IMCI training. The facility had almost all the required nurses (32 nurses against 34 positions). Among them, three nurses received EOC training. 
The headcount of doctors at Bhurungamari Upazila Health Complex indicate the availability of five out of seven doctors: RMO, Consultant-Gyne/Obs, Consultant-Anesthesiology and two Medical Officers. The facility needed to fill in the vacant post of a Consultant-Pediatrics and MO-MCHFP. The facility reported availability of eight nurses against nine positions. There were no EOC and IMCI trained doctor and nurse at the facility.

Human resources situation was poor at Chilmary Upazila Health Complex. There were no RMO, Consultant-Gyne/Obs, and Consultant-Anesthesiology at the facility. The facility had ConsultantPediatrics, MO-MCHFP, and one medical officer against six sanctioned posts. The medical officer was not trained in EOC or IMCI. Fewer than half of the sanctioned nurses were available at Chilmary Upazila Health Complex (6 against 14). None of the nurses had EOC or IMCI training.

Human resources situation in terms of number and training was relatively better at Nageswari Upazila Health Complex, which had almost all required medical professionals: RMO, Consultant-Gyne/Obs, Consultant-Pediatrics, and all four medical officers were in place. However, there was no ConsultantAnesthesiology and MO-MCHFP. Among the available doctors in this facility, two were trained on EOC and other two doctors received IMCI training. There was no shortage of nurses at Nageswari Upazila Health Complex, which had all 13 nurses against the sanctioned positions. Among the nurses, one nurse was trained on EOC and one nurse received IMCI training.

\section{Equipment, logistics and supplies}

Twelve out of fifteen equipment, logistics and supplies were available at Kurigram District Hospital. The facility had anesthesia machine, oxygen cylinder, emergency light, delivery set, sucker machine, ambu bag, nebulizer solution, weighing machine, blood grouping and cross matching reagents, blood bag, doctor's gown, musk and cap, and gloves. However, delivery set was not in working condition. The facility reported non-availability of vacuum extractor, functioning forceps, and neo-natal resuscitator.

Bhurungamari Upazila Health Complex was in the worst condition in terms of the availability of equipment, logistics and supplies. Only seven out of fifteen items were available at the facility. The facility needed anesthesia machine, emergency light, vacuum extractor, functioning forceps, delivery set, sucker machine, blood bag, and doctor's gown, musk and cap.

The availability and condition of equipment, logistics and supplies at Chilmary Upazila Health Complex is nearly similar to that of Bhurungamari Upazila Health Complex. Anesthesia machine, emergency light, vacuum extractor, functioning forceps, nebulizer solution, neo-natal resuscitator, and doctor's gown, musk and cap were not available at Chilmary Upazila Health Complex. However, not all available items were usable. Blood grouping and cross matching reagents, and blood bag were non-usable.

Nageswari Upazila Health Complex was in the best condition in terms of the availability of equipment, logistics and supplies. The facility reported availability of 13 out of 15 items. Nebulizer solution and blood bag were not available at the time of assessment.

Most of the common medicines were available at Kurigram District Hospital. However, Upazila Health Complexes reported unavailability of some common but essential medicines for mother and child. Gentamicin, Erythromycin and Folic Acid were not available at the time of assessment at the Bhurungamari Upazila Health Complex. Chilmary Upazila Health Complex reported unavailability of normal saline, Oxytocin, Gentamycin and Erythromycin. Nageswari Upazila Health Complex did not have the supply of normal saline, Oxytocin injection, Gentamycin and Folic Acid. 


\section{Jamalpur District}

Jamalpur District Hospital and Islampur, Melandah and Bakshiganj Upazila Health Complexes were visited from 31 May to 2 June 2010 to assess the readiness of those facilities for required $\mathrm{MNCH}$ services.

\section{Physical infrastructure}

In the 250-bedded Jamalpur District Hospital, there were 48 female beds (gyne beds: 24 and labor beds: 24). Islampur Upazila Health Complex had 10 female beds, and there were 12 female beds at Melandah and Bakshiganj Upazila Health Complexes each. All four facilities had labor room and beds. There were neonatal beds only at the District Hospital (10 beds).

Condition of labor rooms across the study facilities varied. At the labor room of Jamalpur District Hospital, infection prevention was maintained properly through autoclave-sterilization of instruments and provision of separate waste bins for liquids, solid and sharp. OT at the District Hospital was also in good working condition with proper management of infection prevention. Labor room of Islampur Upazila Health Complex had a mixed condition with all labor instruments autoclaved properly but separate waste bins for liquid, solid and sharp not maintained. In two other Upazila Health Complexes, infection prevention was maintained through the provision of separate waste bins for liquids, solid and sharp.

District Hospital reported uninterrupted supply of electricity with functioning generator only for the OT. None of the Upazila Health Complexes had any generator. All four facilities had modern communication system with land phone, dedicated mobile phone, and computer with internet connections. All facilities prepared and submitted MIS reports timely. District Hospital maintained computer-based MIS. Ambulance was found at all four facilities and also available over phone.

There were necessary staff strength and facilities (obstetrician, pediatrician, and anesthesiologist and blood transfusion with screening) only at the District Hospital for round-the-clock CEmONC services. Only Melandah Upazila Health Complex reported the round-the-clock services with available medical officers trained on gynecology.

\section{Human resources}

In Jamlapur, three out of the four facilities had almost all medical professionals against the sanctioned posts. All four facilities had their managers in place.

District Hospital was in a good functioning condition with available doctors and nurses. The facility had the RMO, one Consultant-Gyne/Obs (against two posts) and Consultant-Anesthesiology in place as well as the required number of Medical Officers against the sanctioned positions. The facility had no Consultant-Pediatrics against the sanctioned post at the time of assessment. However, there was a medical officer trained on Pediatrics. Out of sanctioned four, three Emergency Medical Officers were attached to the facility at the time of assessment. The facility reported availability of 36 nurses against 37 positions, with only one vacancy. Six nurses received EOC training but none had IMCI training.

Human resources situation was good at Islampur Upazila Health Complex. The headcount of doctors at this facility indicates the non-availability of RMO alone. There were required number of ConsultantGyne/Obs, Consultant-Pediatrics, Consultant-Anesthesiology, MO-MCHFP and medical officers at the 
facility. Among the available doctors in this facility, there was one EOC-trained doctor. The facility had 10 nurses with one position being vacant. Among the nurses, one nurse was trained on EOC.

Melandah Upazila Health Complex was the only facility where there was no shortage in the number of doctors against the sanctioned posts. There were RMO, Consultant-Gyne/Obs, Consultant-Pediatrics, Consultant-Anesthesiology, MO-MCHFP and four medical officers as required. There were 10 nurses against 14 sanctioned positions. None of the doctors and nurses was trained on EOC and IMCI.

Human resources situation was poor at Bakshiganj Upazila Health Complex. The facility had the RMO in place. There was no Consultant-Gyne/Obs and Consultant-Pediatrics at the facility. The facility also needed to fill in the vacant post of MO-MCHFP. There was one medical officer against two sanctioned posts. Among the available doctors in this facility, there were two EOC trained and one IMCI trained doctors. Six out of nine nurses were available at the facility. Among them, one nurse was trained on EOC.

\section{Equipment, logistics and supplies}

Nine out of the fifteen equipment, logistics and supplies were available and in working condition at Jamalpur District Hospital during the assessment. The facility did not have emergency light, functioning forceps, nebulizer solution, blood grouping and cross matching reagents, blood bag, and gloves at the time of assessment.

Islampur Upazila Health Complex was in the best condition in terms of the availability of equipment, logistics and supplies. Thirteen out of fifteen items were available at the facility and in working condition. Two equipment that the facility needed were: anesthesia machine and neo-natal resuscitator. The availability and condition of equipment, logistics and supplies at Melandah Upazila Health Complex was nearly similar to that of Islampur Upazila Health Complex. A total of 12 items were available. Anesthesia machine was the only equipment lacking at the facility. Among supplies, blood grouping and cross matching reagents, and doctor's gown, musk and cap were not available during assessment.

Bakshiganj Upazila Health Complex was in a poorer condition in terms of the availability of equipment, logistics and supplies, which reported availability of 8 out of 15 items. The facility needed anesthesia machine, emergency light, vacuum extractor, neo-natal resuscitator, blood grouping and cross matching reagents, blood bag, and doctor's gown, musk and cap.

Most of the common medicines for mother and child except Folic Acid were available at Jamalpur District Hospital and Islampur Upazila Health Complex. Melandah Upazila Health Complex reported unavailability of Gentamicin and Erythromycin. Bakshiganj Upazila Health Complex did not have the supply of Hartman's Solution at the time of assessment.

\section{Thakurgaon District}

In Thakurgaon district, HFA was conducted in District Hospital, Pirganj, Ranishankoil and Baliadangi Upazila Health Complexes from 31 May to 1 June 2010.

\section{Physical infrastructure}

One-fourth of the beds of the 100-bedded District Hospital were allocated as female beds. Among the Upazila Health Complexes, number of female beds varied remarkably from 15 to 34 . Half of the total beds were female beds at Ranishankoil (50 beds), and Pirganj (31 beds) Upazila Health Complexes. At 
the 50-bedded Baliadangi Upazila Health Complex (a CEmONC facility), 34 beds were allocated as female beds. There was the provision of labor beds in all facilities. District Hospital had 18 neonatal beds. Among three Upazila level facilities, Ranishankoil Upazila Health Complex did not allocate any neonatal beds.

Labor rooms in all four facilities were found in a good working condition. District Hospital provides an example of good infection prevention management at the labor room through autoclave-sterilization of instruments and provision of separate waste bins for liquids, solid and sharp. Similar processes were adopted to ensure infection prevention at the OT of District Hospital. Infection prevention through autoclave-sterilization of instruments was practiced at both labor room and OT of Baliadangi Upazila Health Complex. At the Pirganj Upazila Health Complex, all labor instruments were autoclaved properly, while Ranishankoil Upazila Health Complex maintained separate waste bins for liquid, solid, and sharp.

Thakurgaon District Hospital had a generator, which was however, found non-functioning. There was no generator at Baliadangi Upazila Health Complex. Two other Upazila Health Complexes reported emergency supply of electricity through generator. Ambulance was available in all facilities, but its availability over phone was reported in District Hospital, and Pirganj and Ranishankoil Upazila Health Complexes. All facilities had modern communication system with land phone, dedicated mobile phone, and computer. However, computer at Baliadangi Upazila Health Complex was non-functioning. Internet connections were given to District Hospital and Ranishankoil Upazila Health Complex. Data were collected and aggregated systematically by different units of services at each facility. MIS reports were timely prepared and submitted. Only District Hospital maintained computer-based MIS.

There were necessary staff strength and facilities (obstetrician, pediatrician, anesthesiologist and blood transfusion with screening) at both the CEmONC facilities (Thakurgaon District Hospital and Baliadangi Upazila Health Complex) for round-the-clock services.

\section{Human resources}

Analysis of information on the availability of RMO, Consultants in Pediatrics, Gyne/Obs and Anesthesiology, Medical Officers, Emergency Medical Officers and MO-MCH-FP demonstrates a poor condition in terms of headcounts of those service providers at all four facilities in Thakurgaon.

Thakurgaon District Hospital reported having the RMO, one Consultant-Gyne/Obs (against two posts), Consultant-Anesthesiology and three Emergency Medical Officers against the sanctioned positions. However, the facility had no Consultant-Pediatrics, and all four positions of Medical Officers were vacant at the time of assessment. Among the service providers, there were two doctors and six nurses having EOC training while one nurse was trained on IMCI.

At Baliadangi Upazila Health Complex, human resources situation was not sufficient to offer cesarean section delivery services. There were RMO, Consultant-Anesthesiology and two medical officers in place. As the facility offers cesarean section, it is necessary to fill in the post of the ConsultantGyne/Obs on priority basis. There were no Consultant-Pediatrics and MO-MCHFP too. Among the available doctors at this facility, two were trained on EOC and one received IMCI training. Among the nurses, four nurses were trained on EOC and five nurses had IMCI training.

The headcount of doctors at Pirganj Upazila Health Complex indicates the availability of half of the doctors. Consultant-Anesthesiology, MO-MCHFP and two Medical Officers were in place. The facility needed to fill in the vacant post of RMO, Consultant-Gyne/Obs, and two Medical Officers. One doctor and three nurses reported having EOC training, and one doctor and five nurses received IMCI training. 
Human resources situation is unacceptably insufficient at Ranishankoil Upazila Health Complex. There were no RMO, Consultant-Gyne/Obs, Consultant-Pediatrics and Consultant-Anesthesiology at the facility. The facility had one medical officer (against three sanctioned posts) and MO-MCHFP. There were no EOC and IMCI trained doctor and nurse in the facility.

\section{Equipment, logistics and supplies}

Three out of four facilities in Thakurgaon had nearly all essential equipment, logistics and supplies. Fourteen out of 15 equipment, logistics and supplies were available and in working condition at Thakurgaon District Hospital, while only nebulizer solution was not available at the time of assessment. Pirganj and Baliadangi Upazila Health Complexes reported the availability of the same number of equipment, logistics and supplies as the District Hospital. Vacuum extractor was reported unavailable at Pirganj Upazila Health Complex while nebulizer solution was lacking in Baliadangi Upazila Health Complex.

Ranishankoil Upazila Health Complex was in a poorer condition in terms of the availability of equipment, logistics and supplies compared to other facilities. Eleven items were available at Ranishankoil Upazila Health Complex. Items that were unavailable at the facility included: functioning forceps, neo-natal resuscitator, blood grouping and cross matching reagents, and blood bag. There were an anesthesia machine and an oxygen cylinder at the facility, but these equipment were not in a working condition.

Most of the common medicines required for a CEmONC facility were available at Thakurgaon District Hospital, except Hartman's Solution which is very important for delivery complications. Some essential medicines for child illnesses such as Gentamicin, Erythromycin were not available during assessment. At Pirganj and Baliadangi Upazila Health Complexes, most of the essential medicines necessary for mother and child were available. Other than Hartman's Solution all essential medicines necessary for mother and child were available at Ranishankoil Upazila Health Complex. 


\section{DISCUSSIONS AND RECOMMENDATIONS}

A comparative analysis on the availability and condition of physical and human assets across 16 health facilities has been made in this section. Analysis is presented in four broad categories - physical infrastructure; human resources; equipment, logistics and supplies; and medicines - which will tell what is actually needed in a facility in terms of inputs and processes. This information will be fed into for improving facility-based performance and service quality.

\section{A. Physical infrastructure}

Information collected on physical infrastructure was analyzed in terms of building, utility, infection prevention, communication and transportation. The needs of the facilities were assessed.

\section{Building}

- Among all 16 facilities, Bhurungamari Upazila Health Complex did not have any functioning labor room.

- Shaghata Upazila Health Complex did not have any labor beds.

- Seven out of 12 Upazila Health Complexes reported having no neonatal beds. Upazila Health Complexes in Jamalpur did not have any neonatal beds. Neonatal beds were not in place at Sundargonj Upazila Health Complex in Gaibandha, Chilmary and Bhurungamari Upazila Health Complexes in Kurigram, and Ranishoinkal Upazila Health Complex in Thakurgaon.

\section{Generator}

All District Hospitals had the generator. However, the generator in Gaibandha and Thakurgaon District Hospitals were not functional. Most of the Upazila Health Complexes are yet to ensure alternative supply of electricity through generator.

- The generators of Sundargonj and Shaghata Upazila Health Complexes in Gaibandha need to be made functional. Fulchari Upazila Health Complex needs a generator.

- Upazila Health Complexes in Kurigram district reported having the generator, which was, however, not in a working condition.

- None of the Upazila Health Complexes in Jamalpur district had the generator.

- In Thakurgaon district, Baliadangi Upazila Health Complex did not have any generator.

\section{Infection prevention}

All District Hospitals practiced infection prevention through autoclave-sterilization of instruments and provision of separate waste bins for liquid, solid and sharp. Like the District Hospital, most of the Upazila Health Complexes in four districts practiced autoclave-sterilization. However, it was not common among the Upazila Health Complexes to maintain separate waste bins for liquid, solid and sharp.

- At Sundargonj Upazila Health Complex, labor instruments were autoclaved properly. Infection prevention through separate waste bins for liquid, solid and sharp was not practiced at any of the Upazila Health Complexes in Gaibandha. 
- Infection prevention was maintained properly through autoclave-sterilization of instruments at Chilmary and Nageswari Upazila Health Complexes, but separate waste bins for liquid, solid and sharp were not used.

- At Islampur Upazila Health Complex, labor instruments were autoclaved properly but separate waste bins for liquid, solid and sharp not maintained. In two other Upazila Health Complexes in Jamalpur, there were separate waste bins for liquid, solid and sharp.

- Infection prevention through autoclave-sterilization of instruments was practiced of all three Upazila Health Complexes in Thakurgaon. Pirganj Upazila Health Complex did not maintain separate waste bins for liquid, solid and sharp.

\section{Communication and transportation}

All facilities had modern communication system with land phone, dedicated mobile phone, and computer. Most facilities had internet connections. Ambulance was available in all facilities, but its availability over phone was not reported at all Upazila Health Complexes.

\section{B. Human resources}

Analysis of information on the availability of service providers at the facilities indicates that Jamlapur was in the best condition in terms of headcount of doctors, while Gaibandha was in the worst condition. On the other hand, all 16 facilities had most of the required number of nurses. Facilities in Gaibandha were in the best condition in terms of availability of nurses followed by facilities in Jamalpur. There is a clear need for EOC and IMCI training for service providers at all facilities. The following discussion will highlight lackings in health human resources. The analysis was done according to the types of facility.

\section{District Hospital}

- Jamalpur District Hospital had all three types of specialist doctors: one Consultant-Gyne/Obs (against two posts), one Consultant-Anesthesiology, and one medical officer trained in Pediatrics.

- There were no Consultant-Gyne/Obs, Consultant-Anesthesiology and Consultant-Pediatrics at Gaibandha District Hospital.

- Kurigram District Hospitals did not have the Consultants in Pediatrics and Anesthesiology.

- Thakurgaon District Hospital had no Consultant-Pediatrics, and there was one ConsultantGyne/Obs against two posts.

- Several posts of Emergency Medical Officers and Medical Officers remained vacant at the District Hospitals. The situation at Jamalpur and Kurigram District Hospitals was the best where only 1 out of 11 posts needed to be filled in Jamalpur and 1 out of 8 posts in Kurigram. At Gaibandha District Hospital, 3 out of 10 posts of Emergency Medical Officer and Medical Officer remained vacant. Thakurgaon District Hospital had all 3 Emergency Medical Officers while all 4 positions of Medical Officer were vacant. 


\section{Upazila Health Complex}

\section{(i) CEmONC Upazila Health Complex}

- Among 4 CEmONC Upazila Health Complexes across four districts, Islampur Upazila Health Complex, Jamalpur had all required specialist doctors.

- Sundargonj Upazila Health Complex, Gaibandha needed to fill in the vacant post of a Consultant-Pediatrics.

- Nageswari Upazila Health Complex, Kurigram had no Consultant-Anesthesiology. As the facility offers cesarean section, it is necessary to fill in the post of the Consultant-Anesthesiology on priority basis.

- Human resources situation at Baliadangi Upazila Health Complex, Thakurgaon was not sufficient to offer CEmONC services, with lack in Consultant-Gyne/Obs and ConsultantPediatrics.

- Analysis of information of Medical Officers at the CEmONC Upazila Health Complexes reveals the unavailability of Medical Officers at Sundargonj Upazila Health Complex while Islampur, Nageswari and Baliadangi Upazila Health Complexes had the required number of Medical Officers.

\section{(ii) BEmONC Upazila Health Complex}

- Among 8 BEmONC Upazila Health Complexes, Shaghata Upazila Health Complex, Gaibandha did not have any doctors against the sanctioned posts other than the UHFPO.

- Human resources situation is unacceptably insufficient at Fulchari Upazila Health Complex, Gaibandha where only 3 (UHFPO and two medical officers) out of 9 doctors were available.

- Melandah Upazila Health Complex, Jamalpur was the only facility where there was no shortage in the number of doctors against the sanctioned posts.

- Human resources situation was poor at Bakshiganj Upazila Health Complex, Jamalpur with reported availability of half of the doctors. There was vacancy of Consultant-Gyne/Obs, Consultant-Pediatrics, MO-MCHFP and one medical officer (against two sanctioned positions).

- Bhurungamari Upazila Health Complex, Kurigram needed to fill in the vacant post of a Consultant-Pediatrics and MO-MCHFP.

- Availability of human resources was in the poorest condition at Chilmary Upazila Health Complex, Kurigram with the vacancy of RMO, Consultant-Gyne/Obs, ConsultantAnesthesiology and five Medical Officers (against six sanctioned positions).

- The headcount of doctors at Pirganj Upazila Health Complex, Thakurgaon indicates the availability of half of the doctors, with unavailability of RMO, Consultant-Gyne/Obs and two Medical Officers.

- At Ranishankoil Upazila Health Complex, Thakurgaon only 3 (UHFPO, MO-MCHFP and one medical officer) out of 9 doctors were available. It is necessary to fill in the vacancy of RMO, Consultant-Gyne/Obs, Consultant-Pediatrics, Consultant-Anesthesiology and two medical officers. 


\section{Equipment, logistics and supplies}

The following section provides an analysis of information on the availability and status of anesthesia machine, oxygen cylinder, emergency light, vacuum extractor, functioning forceps, delivery set, sucker machine, ambu bag, neo-natal resuscitator, nebulizer solution, weighing machine, blood grouping and cross matching reagents, blood bag, doctor's gown, musk and cap, and gloves. The analysis was done according to the types of facility.

\section{District Hospital}

- Thakurgaon District Hospital was in the best position regarding the availability and condition of equipment, logistics and supplies. Fourteen out of 15 items were available and in working condition at the facility, while only nebulizer solution was not available.

- Twelve out of 15 items were available and in working condition in both Gaibandha and Kurigram District Hospitals. Equipment and supplies that Gaibandha District Hospital needed were: vacuum extractor, neo-natal resuscitator, and nebulizer solution. Kurigram District Hospital needed functioning forceps, vacuum extractor and neo-natal resuscitator.

- Among District Hospitals, Jamalpur District Hospital had the fewest number of items. Nine out of fifteen equipment, logistics and supplies were available and in working condition at the facility. Equipment that Jamalpur District Hospital needed were: emergency light and functioning forceps. Nebulizer solution, blood grouping and cross matching reagents, blood bag, and gloves were needed to be supplied to the facility.

\section{Upazila Health Complex}

\section{(i) CEmONC Upazila Health Complex}

Comparison of availability of equipment, logistics and supplies across four CEmONC Upazila Health Complexes indicates a good condition at all facilities.

- Among the four facilities, Baliadangi Upazila Health Complex was in the best condition. The facility had 14 items of equipment, logistics and supplies. Only nebulizer solution was lacking at the facility.

- Thirteen out of 15 items were available and in working condition at Islampur and Nageswari Upazila Health Complexes. Two equipment that Islampur Upazila Health Complex needed were: anesthesia machine and neo-natal resuscitator. Nageswari Upazila Health Complex needed to make supplies of nebulizer solution and blood bag available.

- Sundargonj Upazila Health Complex had 12 items. Neo-natal resuscitator was the only equipment that the facility needed. Among supplies, nebulizer solution and blood bag were needed at the facility.

\section{(ii) BEmONC Upazila Health Complex}

Among eight BEmONC Upazila Health Complexes, two facilities were in good condition regarding the availability of equipment, logistics and supplies. Pirganj Upazila Health Complex, Thakurgaon was in the best condition followed by Melandah Upazila Health Complex, Jamalpur. Anesthesia machine, a vital instrument required for managing delivery and post-partum complications, was available and in working condition only at Pirganj Upazila Health Complex, Thakurgaon. Among the equipment, vacuum extractor, functioning forceps, and neo-natal resuscitator were reported unavailable by five facilities. 
Among others, supplies like blood grouping and cross matching reagents, and blood bag, and consumable like gloves were the most commonly reported unavailable items. Three facilities did not have delivery set.

- Pirganj Upazila Health Complex, Thakurgaon had 14 out of 15 items of equipment, logistics and supplies. Vacuum extractor was not available at the facility.

- Eleven items were available at Ranishankoil Upazila Health Complex, Thakurgaon. Among available Equipment, anesthesia machine and oxygen cylinder were not in a working condition. Functioning forceps and neo-natal resuscitator were not available at the facility. The facility needed the supplies of blood grouping and cross matching reagents, and blood bag.

- A total of 12 items were available at Melandah Upazila Health Complex, Jamalpur. Anesthesia machine was the only equipment lacking at the facility. Among supplies, blood grouping and cross matching reagents, and doctor's gown, musk and cap were not available.

- Bakshiganj Upazila Health Complex, Jamalpur was in poor condition with the availability of 8 out of 15 items. The facility needed four Equipment: anesthesia machine, emergency light, vacuum extractor, and neo-natal resuscitator. Three types of supplies were needed: blood grouping and cross matching reagents; blood bag; and doctor's gown, musk and cap.

- Eight out of 15 items were available at Fulchari Upazila Health Complex, Gaibandha. Among available Equipment, anesthesia machine was non-functioning. The facility needed four Equipment: vacuum extractor, functioning forceps, delivery set, and neo-natal resuscitator. Three types of supplies were needed: nebulizer solution; blood grouping and cross matching reagents; and blood bag.

- Shaghata Upazila Health Complex, Gaibandha was in a worse condition with only seven items of available Equipment, logistics and supplies. Five key Equipment were lacking at the facility: anesthesia machine, vacuum extractor, functioning forceps, delivery set, and neo-natal resuscitator. Among supplies, blood grouping and cross matching reagents, blood bag, and doctor's gown, musk and cup were not available. There was nebulizer solution, but it was nonusable.

- There was poor availability of Equipment, logistics and supplies at Bhurungamari Upazila Health Complex, Kurigram, where 7 out of 15 items were available. The facility needed six types of Equipment (anesthesia machine, emergency light, vacuum extractor, functioning forceps, delivery set, and sucker machine) and two types of supplies (blood bag, and doctor's gown, musk and cap).

- Chilmary Upazila Health Complex Kurigram was in the worst condition regarding the availability and status of Equipment, logistics and supplies. Anesthesia machine, emergency light, vacuum extractor, functioning forceps, nebulizer solution, neo-natal resuscitator, and doctor's gown, musk and cap were not available at the facility. Among available items, blood grouping and cross matching reagents, and blood bag were non-usable.

\section{Medicines}

All facilities reported availability of most of the essential medicines for mother and child. Kurigram District Hospital, Sundargonj Upazila Health Complex in Gaibandha, and Pirganj and Baliadangi Upazila Health Complexes in Thakurgaon had all the required supplies of essential medicines for mother and 
child. A comparison in the availability of essential medicines for mother and child is made in the following discussion.

\section{District Hospital}

- Kurigram District Hospital was found in the best condition regarding the availability of essential medicines for mother and child, followed by Jamalpur District Hospital that reported unavailability of Folic Acid.

- Five essential medicines for mother and child, e.g., Oxytocin, Hartman's Solution, Folic Acid, Gentamicin and Erythromycin were not available at Gaibandha District Hospital.

- Three essential medicines for mother and child those were not available at Thakurgaon District Hospital included: Hartman's Solution, Gentamicin, and Erythromycin.

\section{Upazila Health Complex}

\section{(i) CEmONC Upazila Health Complex}

- Sundargonj Upazila Health Complex, Gaibandha and Baliadangi Upazila Health Complex, Thakurgaon had the required supplies of essential medicines for mother and child.

- At Islampur Upazila Health Complex, Jamalpur, only Folic Acid was not available.

- Nageswari Upazila Health Complex, Kurigram was in relatively poor condition which did not have the supply of normal saline, Oxytocin injection, Gentamycin and Folic Acid.

\section{(ii) BEmONC Upazila Health Complex}

Four out of eight BEmONC Upazila Health Complexes reported unavailability of Hartman's Solution. Five facilities did not have Gentamicin, while Erythromycin was not available in four facilities. Oxytocin was not available at two facilities. Lack in the important medicines for mother and child is listed below.

- Upazila Health Complexes in Gaibandha reported unavailability of three essential medicines for mother and child each. Oxytocin, Hartman's Solution and Gentamicin were unavailable at Fulchari Upazila Health Complex. Shaghata Upazila Health Complex reported unavailability of Hartman's Solution, Gentamicin and Erythromycin.

- Melandah Upazila Health Complex, Jamalpur reported unavailability of Gentamicin and Erythromycin. Bakshiganj Upazila Health Complex, Jamalpur did not have the supply of Hartman's Solution.

- Upazila Health Complexes in Thakurgaon were in a better position regarding the availability of essential medicines for mother and child. At Pirganj Upazila Health Complex, all important medicines necessary for mother and child were available. Other than Hartman's Solution all essential medicines necessary for mother and child were available at Ranishankoil Upazila Health Complex.

- Gentamicin, Erythromycin and Folic Acid were not available at Bhurungamari Upazila Health Complex. Chilmary Upazila Health Complex reported unavailability of four essential medicines for mother and child: normal saline, Oxytocin, Gentamycin, and Erythromycin. 


\section{WAY FORWARD}

This report is an outcome of the rapid assessment of 16 government health facilities conducted in the preparatory phase of the $\mathrm{P} 4 \mathrm{P}$ project. A comprehensive assessment will be followed before incentiverelated intervention activities can be initiated. Indicators that are to be used for comprehensive assessment (intended for facility accreditation) will be both technical and detailed. There will be more number of indicators for comprehensive assessment (i.e. facility accreditation) than those used for the rapid facility assessment. However, experiences from the rapid assessment will be used to develop necessary instruments for facility accreditation.

More specifically, accreditation of 12 facilities in 3 intervention districts will be carried out through a quality assurance system. To this end, within each district Quality Assurance Group (QAG) will be formed, consisting of a team of technical persons from nearby Medical College, respective District Hospital and professional body. The QAG members will visit the respective health facilities to identify whether the facilities offer a minimal standard of quality of EmONC services. Assessments of facility accreditation will be compared with the findings of rapid assessment in determining the standard of quality of EmONC services at the facilities.

It has emerged from this assessment report that no facility is in a perfect condition to provide quality EmONC services as all the facilities are burdened with problems related to human resources, physical infrastructure, Equipment, logistics and supplies, and medicines. Before initiating the performance-based incentives, the lacking in physical and human assets identified through the rapid facility assessment and facility accreditation must be addressed. Subsequently, the DGHS will be requested to solve the human resource problem. For logistics and Equipment, UNICEF will be intimated to take initiatives. Population Council will be responsible for ensuring the regular supply of medicines and consumables. 
ANNEXURE 
Annexure 1: Facility Assessment Checklist

Introducing Pay-For-Performance (P4P) Approach to Increase Utilization of Maternal, Newborn and Child Health Services in Bangladesh

\section{HEALTH FACILITY ASSESMENT}

2010

\section{(2) Population Council}

House CES (B) 21, Road 118, Gulshan, Dhaka 1212 


\section{FACILITY ASSESMENT QUESTIONNAIRE}

Introducing Pay-For-Performance (P4P) Approach to

Increase Utilization of Maternal, Newborn and Child Health Services in Bangladesh

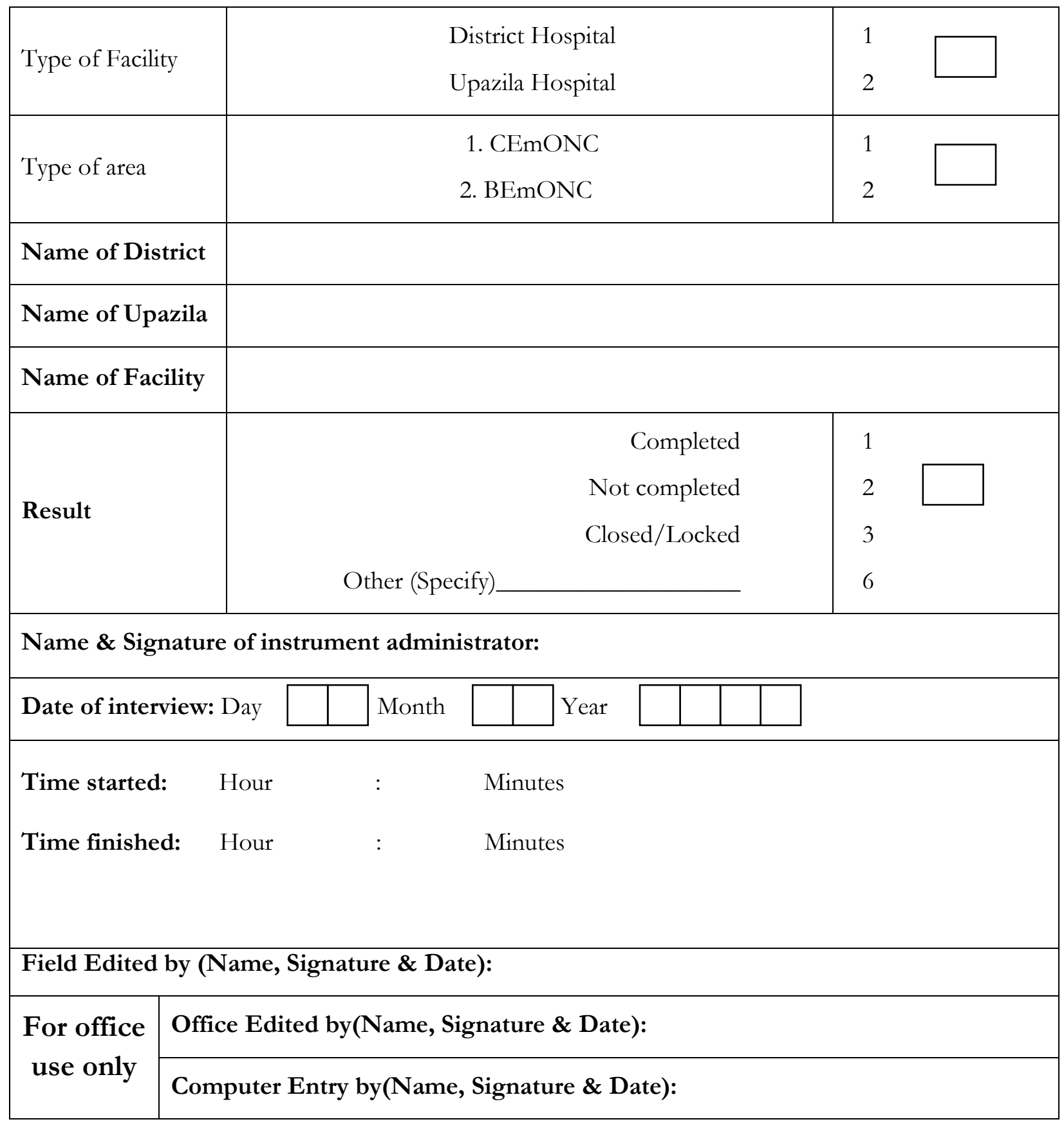

SECTION 1: GENERAL INFORMATION ON INFRASTRUCTURE

(Instruction: Please collect information from MO/RMO/Senior Staff Nurse/Sr.FWV/Midwife) 


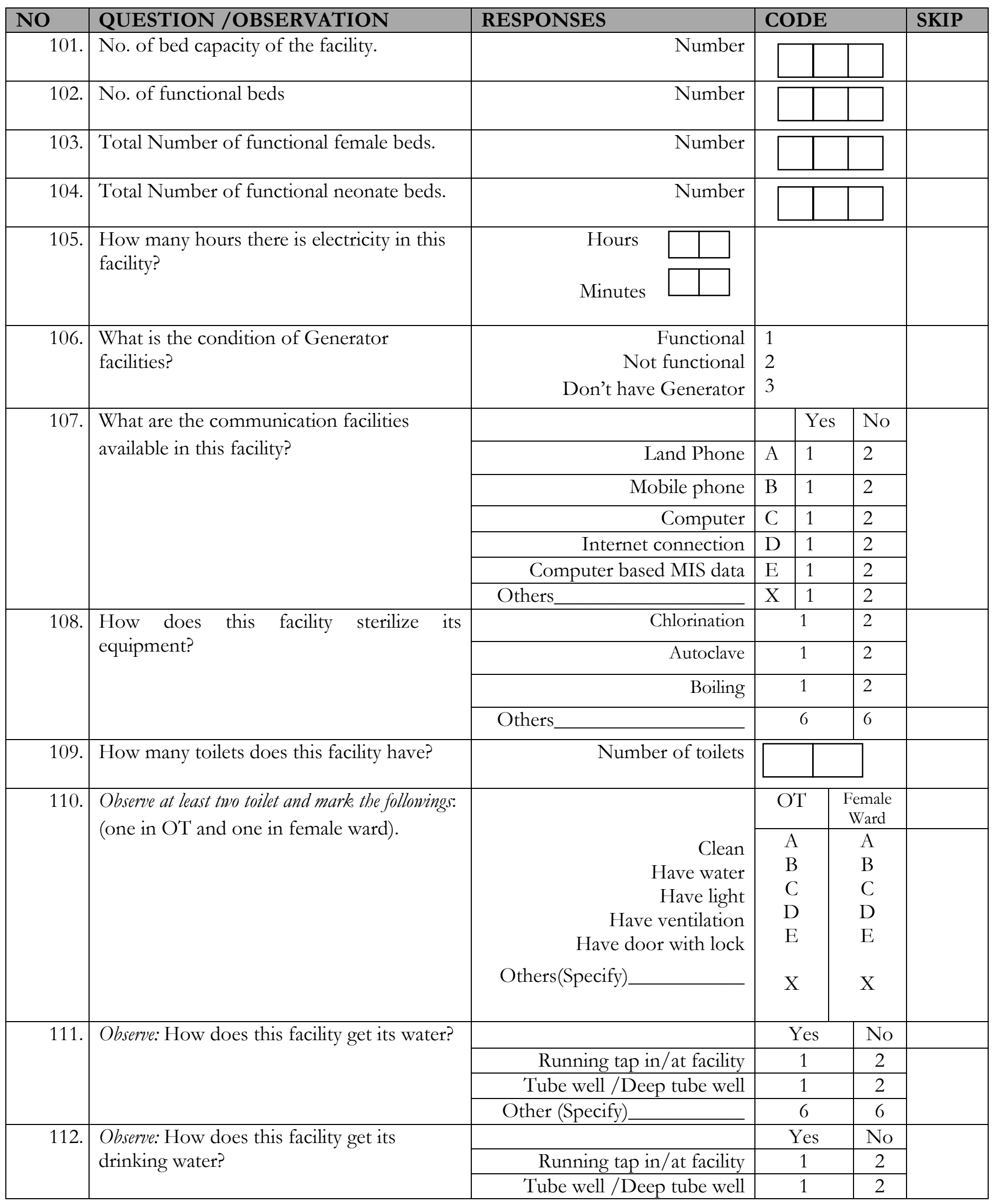




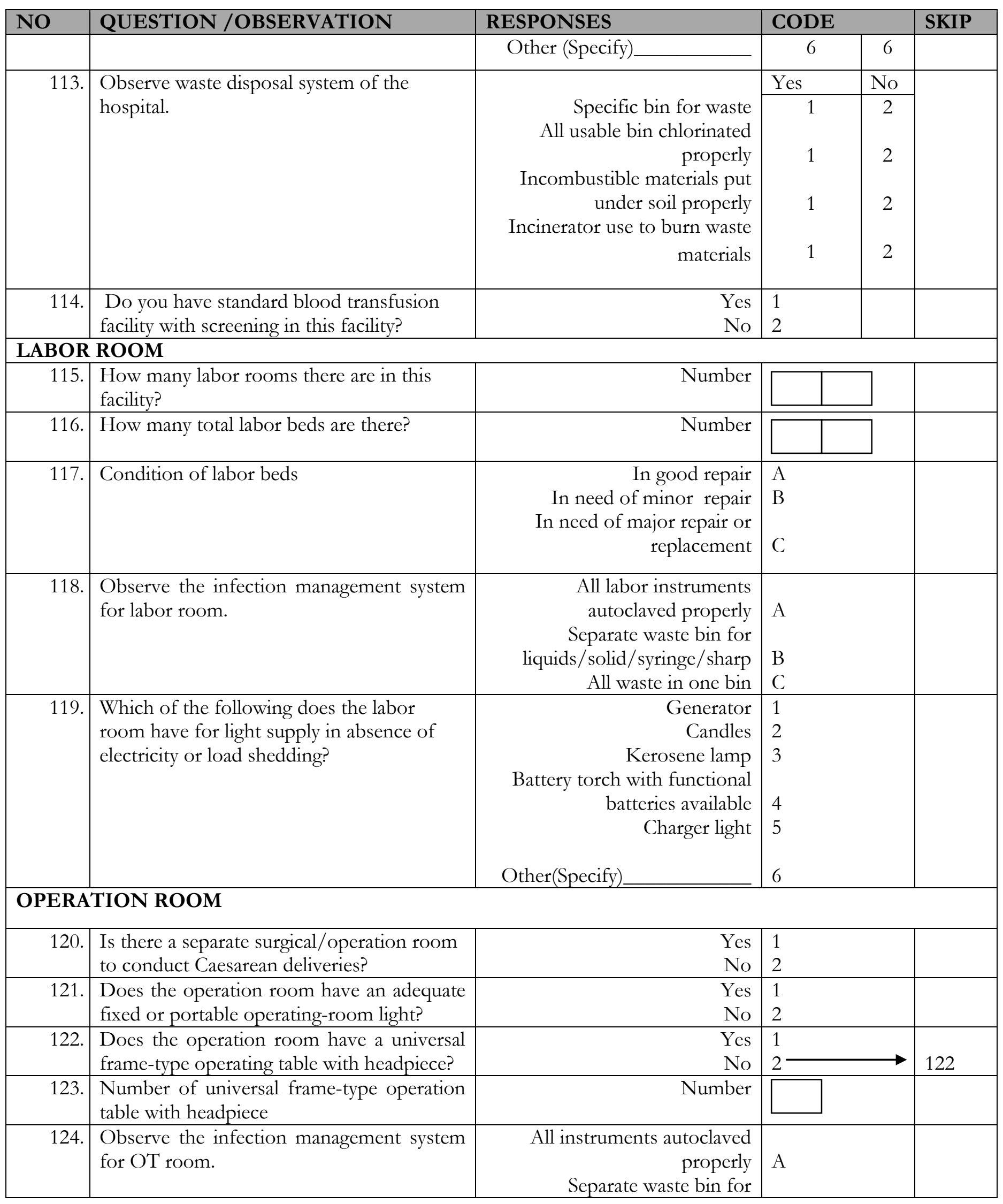




\begin{tabular}{|l|l|r|l|l|}
\hline NO & QUESTION / OBSERVATION & RESPONSES & CODE & SKIP \\
\hline & & liquids/solid/syringe/sharp & B & \\
& All waste in one place & C & \\
\hline
\end{tabular}

Source of Information:

SECTION: 2 HUMAN RESOURCES

(Instruction: Information will be collected from UHFPO/UFPO/MO-MCH (FP)/Statistician)

\begin{tabular}{|c|c|c|c|c|c|}
\hline No. & Name of Post & $\begin{array}{c}\text { Sanctioned } \\
\text { Post }\end{array}$ & $\begin{array}{c}\text { Available } \\
\text { Post }\end{array}$ & $\begin{array}{c}\text { Vacant } \\
\text { Post }\end{array}$ & Remarks \\
\hline $201 . \mathrm{a}$ & \multicolumn{5}{|l|}{ Health (District hospital) } \\
\hline & Civil Surgeon & & & & \\
\hline & Superintendent & & & & \\
\hline & Senior Consultant ( Gyn \& Obs ) & & & & \\
\hline & Senior Consultant ( Padiatrics ) & & & & \\
\hline & Residential Medical Officer ( RMO ) & & & & \\
\hline & Consultant ( Gyn \& Obs ) & & & & \\
\hline & Consultant (Anesthesia) & & & & \\
\hline & MO (Anesthesia) & & & & \\
\hline & Assist. Register ( Gye \& Obs ) & & & & \\
\hline & Assist. Register (Paediatrics ) & & & & \\
\hline & Emergency Medical Officer & & & & \\
\hline & Medical Officer ( Gye \& Obs ) & & & & \\
\hline & Medical Officer (Paediatrics) & & & & \\
\hline & Medical Officer (Blood Bank) & & & & \\
\hline & Consultant ( Radiology ) & & & & \\
\hline & Consultant ( Pathology) & & & & \\
\hline & Sr. Staff Nurse & & & & \\
\hline & Assist. Nurse & & & & \\
\hline & Medical Technologist ( Lab ) & & & & \\
\hline
\end{tabular}




\begin{tabular}{|c|c|c|c|c|c|}
\hline \multirow[t]{2}{*}{ No. } & Name of Post & $\begin{array}{c}\text { Sanctioned } \\
\text { Post }\end{array}$ & $\begin{array}{c}\text { Available } \\
\text { Post }\end{array}$ & $\begin{array}{c}\text { Vacant } \\
\text { Post }\end{array}$ & Remarks \\
\hline & Medical Technologist ( Blood Bank) & & & & \\
\hline & Medical Technologist ( Radiography) & & & & \\
\hline & Pharmacist & & & & \\
\hline & Deputy Nursing Superintendent & & & & \\
\hline & Nursing Supervisor & & & & \\
\hline & Head Asstt. Cum Accountant & & & & \\
\hline & Statistician & & & & \\
\hline & Store Keeper & & & & \\
\hline & MLSS & & & & \\
\hline & Cook/ Mashalchi & & & & \\
\hline & Sweeper & & & & \\
\hline & Security Guard & & & & \\
\hline & Stretcher Bearer & & & & \\
\hline & Ambulance Driver & & & & \\
\hline & Family Planning Unit & & & & \\
\hline & DD-Family Planning & & & & \\
\hline 201.b & $\begin{array}{l}\text { Health Unit (Upazila health } \\
\text { complex) }\end{array}$ & & & & \\
\hline & $\begin{array}{l}\text { Upazila Health and Family Planning } \\
\text { Officer }\end{array}$ & & & & \\
\hline & $\begin{array}{l}\text { Jr. Consultant (Gynecology \& } \\
\text { Obstetric) }\end{array}$ & & & & \\
\hline & Jr. Consultant (Pediatrics) & & & & \\
\hline & Jr. Consultant (Anesthesia) & & & & \\
\hline & Residential Medical Officer & & & & \\
\hline & Emergency Medical Officer & & & & \\
\hline & Medical Officer & & & & \\
\hline & Pathologist & & & & \\
\hline & Sr. Staff Nurse & & & & \\
\hline & Asst. Nurse & & & & \\
\hline & Medical Technologist(Lab) & & & & \\
\hline
\end{tabular}




\begin{tabular}{|l|l|l|l|l|l|}
\hline No. & \multicolumn{1}{|c|}{ Name of Post } & $\begin{array}{c}\text { Sanctioned } \\
\text { Post }\end{array}$ & $\begin{array}{c}\text { Available } \\
\text { Post }\end{array}$ & $\begin{array}{c}\text { Vacant } \\
\text { Post }\end{array}$ & Remarks \\
\hline & Medical Technologist (EPI) & & & & \\
\hline & Pharmacist & & & & \\
\hline & Statistician & & & & \\
\hline & Head Assistant & & & & \\
\hline & Office Assistant & & & & \\
\hline & Driver for ambulance & & & \\
\hline & Aya & & & & \\
\hline & Ward Boy & & & & \\
\hline & Cleaner/ Sweeper & & & & \\
\hline & Night Guard & & & & \\
\hline
\end{tabular}

\begin{tabular}{|l|l|l|l|l|l|l|}
\hline No. & \multicolumn{1}{|c|}{ Name of Post } & $\begin{array}{c}\text { Sanctioned } \\
\text { Post }\end{array}$ & $\begin{array}{c}\text { Available } \\
\text { Post }\end{array}$ & \multicolumn{1}{|c|}{$\begin{array}{c}\text { Vacant } \\
\text { Post }\end{array}$} & \multicolumn{2}{|l|}{ Remarks } \\
\hline 201.c & Family Planning Unit & & & & \\
\hline & UFPO & & & & \\
\hline & MO (MCH-FP) & & & & \\
\hline & AUFPO & & & & \\
\hline & UFPA & & & & \\
\hline & Office Assistant & & & & \\
\hline & SACMO & & & & \\
\hline & FWV & & & & \\
\hline & FWA & & & & \\
\hline & Midwives & & & & \\
\hline & Pharmacist & & & & \\
\hline & Aya & & & & \\
\hline & MLSS & & & & \\
\hline & Night Guard & & & \\
\hline & Driver & & & \\
\hline
\end{tabular}

\section{Source of Information:}




\section{Training Issues}

\begin{tabular}{|c|l|c|c|}
\hline \multicolumn{2}{|l|}{$\begin{array}{l}\text { 201. d Do the providers have the following } \\
\text { trainings? }\end{array}$} & $\begin{array}{c}\text { Number of trained } \\
\text { doctor }\end{array}$ & $\begin{array}{c}\text { Number of trained } \\
\text { nurse }\end{array}$ \\
\hline 1 & EOC & & \\
\hline 2 & Safe motherhood/life-saving skills & & \\
\hline 3 & $\begin{array}{l}\text { Integrated management of childhood } \\
\text { illness (IMCI) }\end{array}$ & & \\
\hline 4 & Drug and supplies management & & \\
\hline 5 & Infection prevention & & \\
\hline 6 & Waste management & & \\
\hline 7 & Blood Transfusion & & \\
\hline
\end{tabular}

\section{Source of Information:}




\section{SECTION: 3 Signal function performed at facility}

\section{(Instruction: Information will be collected from MO/RMO/Nurse)}

\begin{tabular}{|c|c|c|c|c|c|}
\hline NO & $\begin{array}{l}\text { QUESTION/OBSERVATIO } \\
\mathbf{N}\end{array}$ & RESPONSE & CODE & $\begin{array}{l}\text { If no in past } 3 \\
\text { months, why? }\end{array}$ & CODE \\
\hline 301. & $\begin{array}{l}\text { Does this facility administer } \\
\text { parental antibiotics to mother } \\
\text { and child? }\end{array}$ & $\begin{array}{r}\text { During last three } \\
\text { months } \\
\text { During last six months } \\
\text { Never performed }\end{array}$ & $\begin{array}{l}1 \\
2 \\
3\end{array}$ & $\begin{array}{r}\text { Training issues } \\
\text { Supplies/ } \\
\text { equipment/ drugs } \\
\text { issue } \\
\text { Management issue } \\
\text { Policy issues } \\
\text { No indication }\end{array}$ & $\begin{array}{l}\text { A } \\
\text { B } \\
\text { C } \\
\text { D } \\
\text { E }\end{array}$ \\
\hline 302. & $\begin{array}{l}\text { Does this facility administer } \\
\text { utero-tonic drugs (Oxytocin) to } \\
\text { mother? }\end{array}$ & $\begin{array}{r}\text { During last three } \\
\text { months } \\
\text { During last six months } \\
\text { Never performed }\end{array}$ & $\begin{array}{l}1 \\
2 \\
3\end{array}$ & $\begin{array}{r}\text { Training issues } \\
\text { Supplies/ } \\
\text { equipment/ drugs } \\
\text { issue } \\
\text { Management issue } \\
\text { Policy issues } \\
\text { No indication }\end{array}$ & $\begin{array}{l}\text { A } \\
\text { B } \\
\text { C } \\
\text { D } \\
\text { E }\end{array}$ \\
\hline 303. & \begin{tabular}{llr} 
Does this facility administer & \multicolumn{2}{c}{ ad } \\
anticonvulsant drug for \\
Eclampsia & (magnesium \\
sulphate? & &
\end{tabular} & $\begin{array}{r}\text { During last three } \\
\text { months } \\
\text { During last six months } \\
\text { Never performed }\end{array}$ & $\begin{array}{l}1 \\
2 \\
3\end{array}$ & $\begin{array}{r}\text { Training issues } \\
\text { Supplies/ } \\
\text { equipment/ drugs } \\
\text { issue } \\
\text { Management issue } \\
\text { Policy issues } \\
\text { No indication }\end{array}$ & $\begin{array}{l}\text { A } \\
\text { B } \\
\text { C } \\
\text { D } \\
\text { E }\end{array}$ \\
\hline 304. & $\begin{array}{l}\text { Does this facility perform } \\
\text { manual removal of placenta? }\end{array}$ & $\begin{array}{r}\text { During last three } \\
\text { months } \\
\text { During last six months } \\
\text { Never performed }\end{array}$ & $\begin{array}{l}1 \\
2 \\
3\end{array}$ & $\begin{array}{r}\text { Training issues } \\
\text { Supplies/ } \\
\text { equipment/ drugs } \\
\text { issue } \\
\text { Management issue } \\
\text { Policy issues } \\
\text { No indication }\end{array}$ & $\begin{array}{l}\text { A } \\
\text { B } \\
\text { C } \\
\text { D } \\
\text { E }\end{array}$ \\
\hline 305. & $\begin{array}{l}\text { Does this facility perform } \\
\text { removal of retained product } \\
\text { (manual vacuum extraction, } \\
\text { dilatation and curettage)? }\end{array}$ & $\begin{array}{r}\text { During last three } \\
\text { months } \\
\text { During last six months } \\
\text { Never performed }\end{array}$ & $\begin{array}{l}1 \\
2 \\
3\end{array}$ & $\begin{array}{r}\text { Training issues } \\
\text { Supplies/ } \\
\text { equipment/ drugs } \\
\text { issue } \\
\text { Management issue } \\
\text { Policy issues } \\
\text { No indication }\end{array}$ & $\begin{array}{l}\text { A } \\
\text { B } \\
\text { C } \\
\text { D } \\
\text { E }\end{array}$ \\
\hline 306. & $\begin{array}{l}\text { Does this facility perform } \\
\text { assisted vaginal delivery like } \\
\text { forceps delivery, vacuum } \\
\text { extraction)? }\end{array}$ & $\begin{array}{r}\text { During last three } \\
\text { months } \\
\text { During last six months } \\
\text { Never performed }\end{array}$ & $\begin{array}{l}1 \\
2 \\
3\end{array}$ & $\begin{array}{r}\text { Training issues } \\
\text { Supplies/ } \\
\text { equipment/ drugs } \\
\text { issue } \\
\text { Management issue } \\
\text { Policy issues } \\
\text { No indication }\end{array}$ & $\begin{array}{l}\text { A } \\
\text { B } \\
\text { C } \\
\text { D } \\
\text { E }\end{array}$ \\
\hline
\end{tabular}




\begin{tabular}{|c|c|c|c|c|c|}
\hline NO & $\begin{array}{l}\text { QUESTION/OBSERVATIO } \\
\mathbf{N}\end{array}$ & RESPONSE & CODE & $\begin{array}{l}\text { If no in past } 3 \\
\text { months, why? }\end{array}$ & CODE \\
\hline 307. & $\begin{array}{l}\text { Does this facility perform } \\
\text { neonatal resuscitation with } \\
\text { Ambu bag? }\end{array}$ & $\begin{array}{r}\text { During last three } \\
\text { months } \\
\text { During last six months } \\
\text { Never performed }\end{array}$ & $\begin{array}{l}1 \\
2 \\
3\end{array}$ & $\begin{array}{r}\text { Training issues } \\
\text { Supplies/ } \\
\text { equipment/ drugs } \\
\text { issue } \\
\text { Management issue } \\
\text { Policy issues } \\
\text { No indication }\end{array}$ & $\begin{array}{l}\text { A } \\
\text { B } \\
\text { C } \\
\text { D } \\
\text { E }\end{array}$ \\
\hline 308. & $\begin{array}{l}\text { Does this facility perform } \\
\text { surgery }(\mathrm{C} / \mathrm{S}) \text { ? }\end{array}$ & $\begin{array}{r}\text { During last three } \\
\text { months } \\
\text { During last six months } \\
\text { Never performed }\end{array}$ & $\begin{array}{l}1 \\
2 \\
3\end{array}$ & $\begin{array}{r}\text { Training issues } \\
\text { Supplies/ } \\
\text { equipment/ drugs } \\
\text { issue } \\
\text { Management issue } \\
\text { Policy issues } \\
\text { No indication }\end{array}$ & $\begin{array}{l}\text { A } \\
\text { B } \\
\text { C } \\
\text { D } \\
\text { E }\end{array}$ \\
\hline 309. & $\begin{array}{l}\text { Does this facility perform blood } \\
\text { transfusion with screening? }\end{array}$ & $\begin{array}{r}\text { During last three } \\
\text { months } \\
\text { During last six months } \\
\text { Never performed }\end{array}$ & $\begin{array}{l}1 \\
2 \\
3\end{array}$ & $\begin{array}{r}\text { Training issues } \\
\text { Supplies/ } \\
\text { equipment/ drugs } \\
\text { issue } \\
\text { Management issue } \\
\text { Policy issues } \\
\text { No indication } \\
\end{array}$ & $\begin{array}{l}\mathrm{A} \\
\mathrm{B} \\
\mathrm{C} \\
\mathrm{D} \\
\mathrm{E}\end{array}$ \\
\hline
\end{tabular}

Source of Information:

SECTION: 4 AVAILABILITY OF TRANSPORTATION FACILITIES

(Instruction: Information will be collected from MO/RMO/Nurse/Sr.FWV/Midwife)

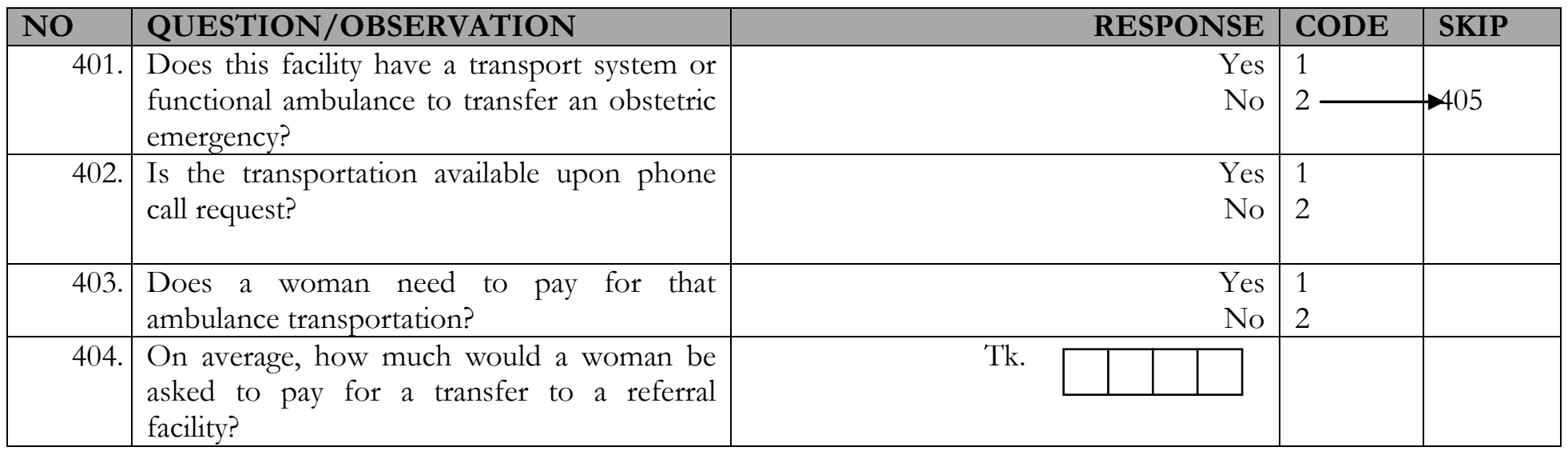




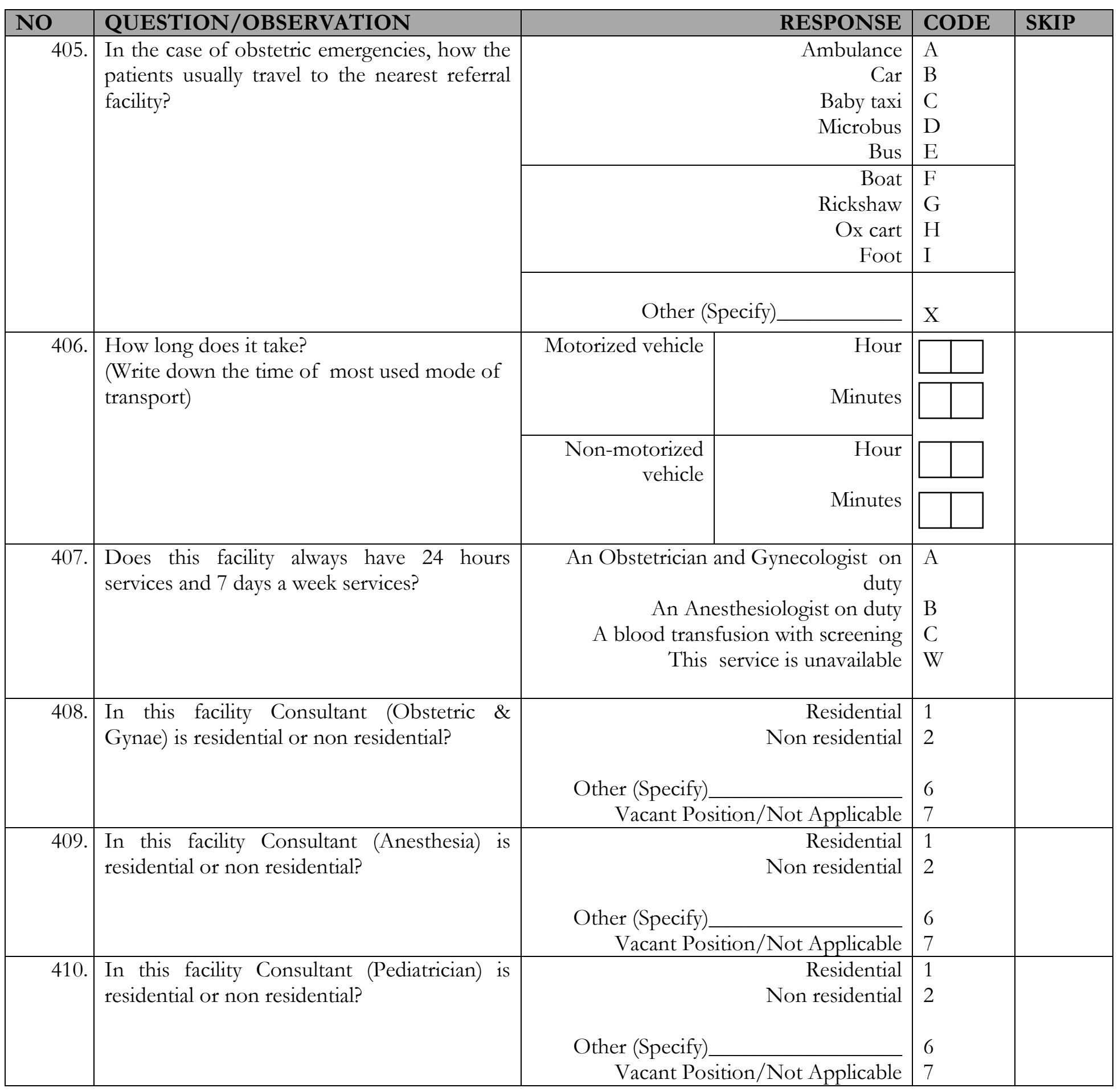




\section{SECTION: 5 INFORMATION ON EQUIPMENT, LOGISTICS \& SUPPLIES}

(Source: Please collect information from OT in charge/ Consultant (Gynae)/ MO, Store keeperHealth, Store keeper- FP, MO-MCH (FP), Sr. FWV)

\begin{tabular}{|c|c|c|c|c|}
\hline NO & QUESTION /OBSERVATION & RESPONSES & CODE & SKIP \\
\hline \multirow[t]{6}{*}{501.} & $\begin{array}{l}\text { Where is most equipment stored? } \\
\text { (Observe where equipment is stored) }\end{array}$ & & & \\
\hline & a. Delivery set? & $\begin{array}{l}\text { In a locked cabinet/Store } \\
\text { On an unlocked shelf/Place }\end{array}$ & $\begin{array}{l}1 \\
2\end{array}$ & \\
\hline & b. Ventose? & $\begin{array}{l}\text { In a locked cabinet/Store } \\
\text { On an unlocked shelf/Place }\end{array}$ & $\begin{array}{l}1 \\
2\end{array}$ & \\
\hline & c. Forceps? & $\begin{array}{l}\text { In a locked cabinet/Store } \\
\text { On an unlocked shelf/Place }\end{array}$ & $\begin{array}{l}1 \\
2\end{array}$ & \\
\hline & d. D\&C set? & $\begin{array}{l}\text { In a locked cabinet/Store } \\
\text { On an unlocked shelf/Place }\end{array}$ & $\begin{array}{l}1 \\
2\end{array}$ & \\
\hline & e. $\mathrm{C} / \mathrm{S}$ set? & $\begin{array}{l}\text { In a locked cabinet/Store } \\
\text { On an unlocked shelf/Place }\end{array}$ & $\begin{array}{l}1 \\
2\end{array}$ & \\
\hline 502. & $\begin{array}{l}\text { Observe if each item is available. If yes, } \\
\text { ask if it is in working condition. If not } \\
\text { available move to the next item. }\end{array}$ & $\begin{array}{c}\text { Available? } \\
\text { YES }=1 \\
\mathrm{NO}=2\end{array}$ & $\begin{array}{l}\text { Working? } \\
\text { YES }=1 \\
\mathrm{NO}=2\end{array}$ & \\
\hline \multicolumn{5}{|c|}{ Equipment, Logistics and supplies } \\
\hline 1 & Anaesthesia Machine & & & \\
\hline 2 & Pulse Oximeter with Monitor & & & \\
\hline 3 & Oxygen Cylinder & & & \\
\hline 4 & Nitrous Oxide Cylinder & & & \\
\hline 5 & $\begin{array}{l}\text { Light Emergency (torch? Generator? } \\
\text { Solar powered?) }\end{array}$ & & & \\
\hline 6 & Electric Sterilizer & & & \\
\hline 7 & Sterilizer non electric & & & \\
\hline 8 & Vacuum extractor & & & \\
\hline 9 & Functioning Forceps & & & \\
\hline 10 & Centre Spot Light & & & \\
\hline 11 & Craniotomy set & & & \\
\hline 12 & Caesarean set (Number of sets) & & & \\
\hline 13 & Delivery set & & & \\
\hline 14 & Sucker machine & & & \\
\hline 15 & Ambu bag & & & \\
\hline
\end{tabular}




\begin{tabular}{|c|c|c|c|c|}
\hline NO & QUESTION /OBSERVATION & RESPONSES & CODE & SKIP \\
\hline 16 & Uterus Evacuation set & & & \\
\hline 17 & Radian Warmer & & & \\
\hline 18 & Neonatal resuscitator & & & \\
\hline 19 & Laryngoscope set & & & \\
\hline 20 & Pump suction & & & \\
\hline 21 & $\begin{array}{l}\text { Sphygnomanometer (neonate, } \\
\text { electronic) }\end{array}$ & & & \\
\hline 22 & $\begin{array}{l}\text { Hub cutter- Syringe, Mucus } \\
\text { extractor }\end{array}$ & & & \\
\hline 23 & I/V Cannula (24G/26G), & & & \\
\hline 24 & $\begin{array}{l}\text { Sterile Equipment for cord cutting } \\
\& \text { drying }\end{array}$ & & & \\
\hline 25 & Feeding Tube & & & \\
\hline 26 & $\begin{array}{l}\text { Blood grouping and cross matching } \\
\text { reagents }\end{array}$ & & & \\
\hline 27 & Blood bag & & & \\
\hline 28 & Doctor's gown, musk and cap & & & \\
\hline 29 & Gloves & & & \\
\hline 30 & RPR kit & & & \\
\hline 31 & HIV Testing kit & & & \\
\hline 32 & Hepatitis B virus testing kit & & & \\
\hline 33 & Hepatitis $C$ virus testing kit & & & \\
\hline 34 & Malaria screening reagent & & & \\
\hline 35 & Haemoglobin test & & & \\
\hline 36 & Complete Blood Count (CBC) & & & \\
\hline 37 & Mobile Operating light & & & \\
\hline 38 & $\begin{array}{l}\text { Needle Spinal Ster Disp (EOC)- 22/ } \\
27 \text { gauge }\end{array}$ & & & \\
\hline 39 & Umbilical cord clamp & & & \\
\hline 40 & Bag, urine collection, $2000 \mathrm{ml}$ & & & \\
\hline 41 & Folye's Catheter & & & \\
\hline 42 & Cannula, 22G/24g, disposable & & & \\
\hline 43 & Catheter, foley's-14,16 & & & \\
\hline
\end{tabular}




\begin{tabular}{|c|c|c|c|c|}
\hline NO & QUESTION /OBSERVATION & RESPONSES & CODE & SKIP \\
\hline \multicolumn{5}{|c|}{ Medicine } \\
\hline 1 & Inj. Diazepam & & & \\
\hline 2 & Inj. Ergometrin & & & \\
\hline 3 & Inj. Oxytocin & & & \\
\hline 4 & Tab. Misoprostol & & & \\
\hline 5 & Inj. Magnesium Sulphate & & & \\
\hline 6 & Inj. Adrenaline & & & \\
\hline 7 & Inj. Ephidrine & & & \\
\hline 8 & Inj. Aminophylline & & & \\
\hline 9 & Inj. Hydrocortisone & & & \\
\hline 10 & Anaesthetics and resuscitation drugs & & & \\
\hline 11 & Inj. Pentothal & & & \\
\hline 12 & Inj. Atropine & & & \\
\hline 13 & Inj. Prostigmine & & & \\
\hline 14 & Inj. Ketamine & & & \\
\hline 15 & Inj. Xylocaine & & & \\
\hline 16 & Inj. Flaxedil & & & \\
\hline 17 & Ultracaine heavy & & & \\
\hline 18 & Inj. Ciproprocin & & & \\
\hline 19 & Inj. Gentamicine & & & \\
\hline 20 & Suxamethorium & & & \\
\hline 21 & Inj. Neostegmin & & & \\
\hline 22 & Inj. Fentanyl & & & \\
\hline 23 & Inj. Nocuron & & & \\
\hline 24 & Sedil & & & \\
\hline 25 & Normal saline & & & \\
\hline 26 & Dextrose saline & & & \\
\hline 27 & Hartman's Solution & & & \\
\hline 28 & Plasma expanders & & & \\
\hline 29 & Endotracheal tube & & & \\
\hline 30 & Spinal needle & & & \\
\hline 31 & Infusion set & & & \\
\hline
\end{tabular}




\begin{tabular}{|c|c|c|c|c|}
\hline NO & QUESTION /OBSERVATION & RESPONSES & CODE & SKIP \\
\hline 32 & IV Canula & & & \\
\hline 33 & $\begin{array}{l}\text { Ceftriaxone, injection } \\
250 \mathrm{mg} / 500 \mathrm{mg} / 1 \mathrm{~g} / 2 \mathrm{~g}\end{array}$ & & & \\
\hline 34 & Chloramphenicol, injection $1 \mathrm{~g}$ & & & \\
\hline 35 & $\begin{array}{l}\text { Chlorhexidine concentrate, } 5 \% \\
\text { solution }\end{array}$ & & & \\
\hline 36 & Chloroquine, tablets $150 \mathrm{mg}$ & & & \\
\hline 37 & Cloxacillin, injection $500 \mathrm{mg}$ & & & \\
\hline 38 & $\begin{array}{l}\text { Co-trimoxazole, tablets } \\
(400 \mathrm{mg}+80 \mathrm{mg})\end{array}$ & & & \\
\hline \multicolumn{5}{|c|}{ Medicine and Equipment for children } \\
\hline 1 & ARI timer (functioning) & & & \\
\hline 2 & Weight machine & & & \\
\hline 3 & Feeding tube & & & \\
\hline 4 & Nebulise solution & & & \\
\hline 5 & ORS & & & \\
\hline 6 & Cap-Vit A, Blue capsule & & & \\
\hline 7 & Cap-Vit A, Red capsule & & & \\
\hline 8 & $\begin{array}{l}\text { Tab Paed- Co-trimoxazole (120 } \\
\text { mg)/ solution }\end{array}$ & & & \\
\hline 9 & Tab- Co-trimoxazole (480 mg) & & & \\
\hline 10 & Susp. Cotrimixazole & & & \\
\hline 11 & Tab. Paracetamol & & & \\
\hline 12 & Syp. Paracetamol & & & \\
\hline 13 & Inj. Gentamicin (20mg) & & & \\
\hline 14 & Inj. Gentamicin (80mg) & & & \\
\hline 15 & Inj. Ampicilin (250mg) & & & \\
\hline 16 & Inj. Benzyle penicillin (1 lac IU) & & & \\
\hline 17 & Susp. Amoxycilin (bottle) & & & \\
\hline 18 & Tab. Erythromycin (250 mg) & & & \\
\hline 19 & Susp. Erythromycin (bottle) & & & \\
\hline 20 & Cap. Tetracycline (250 mg) & & & \\
\hline 21 & Cap. Doxicycline $(100 \mathrm{mg})$ & & & \\
\hline
\end{tabular}




\begin{tabular}{|l|l|l|l|l|}
\hline NO & QUESTION /OBSERVATION & RESPONSES & CODE & SKIP \\
\hline 22 & Erythromycin syrup, $50 \mathrm{mg} / \mathrm{kg}$ & & & \\
\hline 23 & Ether anaesthetic & & & \\
\hline 24 & $\begin{array}{l}\text { Ferrous salt }+ \text { folic acid, tablet } \\
60 \mathrm{mg}+0.25 \mathrm{mg}\end{array}$ & & & \\
\hline 25 & Folic acid, tablet $1 \mathrm{mg}$ & & & \\
\hline 26 & Furosemide $10 \mathrm{mg} / \mathrm{ml}$, injection $2 \mathrm{ml}$ & & & \\
\hline 27 & Norethisterone, tablets $5 \mathrm{mg}$ & & & \\
\hline
\end{tabular}

\section{SECTION: 6 MIS (INFROMATION OF REGISTER and GUIDELINES)}

(Instruction: Information will be collected from MO/RMO/Senior Staff Nurse)

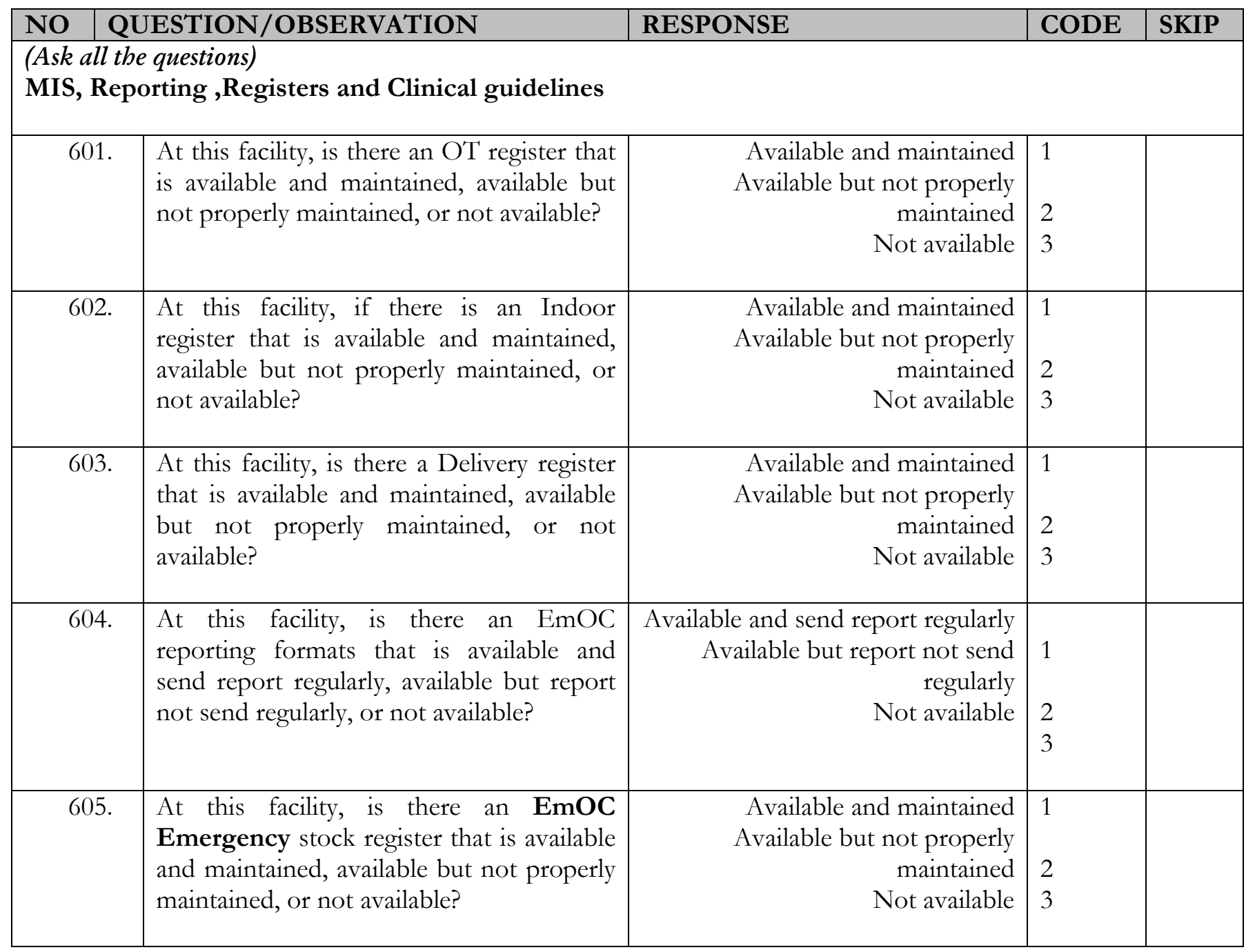




\begin{tabular}{|c|c|c|c|c|c|}
\hline NO & QUESTION/OBSERVATION & \multicolumn{2}{|l|}{ RESPONSE } & CODE & SKIP \\
\hline 606 & $\begin{array}{l}\text { At this facility, is there an antenatal } \\
\text { register for health that is available and } \\
\text { maintained available but not properly } \\
\text { maintained or not available? }\end{array}$ & \multicolumn{2}{|c|}{$\begin{array}{r}\text { Available and maintained } \\
\text { Available but not properly } \\
\text { maintained } \\
\text { Not available }\end{array}$} & $\begin{array}{l}1 \\
2 \\
3\end{array}$ & \\
\hline 607. & $\begin{array}{l}\text { At this facility, is there an antenatal } \\
\text { register for FP that is available and } \\
\text { maintained available but not properly } \\
\text { maintained or not available? }\end{array}$ & \multicolumn{2}{|c|}{$\begin{array}{r}\text { Available and maintained } \\
\text { Available but not properly } \\
\text { maintained } \\
\text { Not available }\end{array}$} & $\begin{array}{l}1 \\
2 \\
3\end{array}$ & \\
\hline 608. & $\begin{array}{l}\text { At this facility, is there a postnatal } \\
\text { register for health that is available and } \\
\text { maintained available but not properly } \\
\text { maintained or not available? }\end{array}$ & \multicolumn{2}{|c|}{$\begin{array}{r}\text { Available and maintained } \\
\text { Available but not properly } \\
\text { maintained } \\
\text { Not available }\end{array}$} & $\begin{array}{l}1 \\
2 \\
3\end{array}$ & \\
\hline 609. & $\begin{array}{l}\text { At this facility, is there a postnatal } \\
\text { register for FP that is available and } \\
\text { maintained available but not properly } \\
\text { maintained or not available? }\end{array}$ & \multicolumn{2}{|c|}{$\begin{array}{r}\text { Available and maintained } \\
\text { Available but not properly } \\
\text { maintained } \\
\text { Not available }\end{array}$} & $\begin{array}{l}1 \\
2 \\
3\end{array}$ & \\
\hline 610. & $\begin{array}{l}\text { At this facility is there a Family planning } \\
\text { register or log book that is available and } \\
\text { maintained available but not properly } \\
\text { maintained or not available? }\end{array}$ & \multicolumn{2}{|c|}{$\begin{array}{r}\text { Available and maintained } \\
\text { Available but not properly } \\
\text { maintained } \\
\text { Not available }\end{array}$} & $\begin{array}{l}1 \\
2 \\
3\end{array}$ & \\
\hline 611. & $\begin{array}{l}\text { At this facility, is there an IMCI reporting } \\
\text { formats that is available and send report } \\
\text { regularly, available but report not send } \\
\text { regularly, or not available? }\end{array}$ & \multicolumn{2}{|c|}{$\begin{array}{r}\text { Available and send report regularly } \\
\text { Available but report not send } \\
\text { regularly } \\
\text { Not available }\end{array}$} & $\begin{array}{l}1 \\
2 \\
3\end{array}$ & \\
\hline \multirow[t]{5}{*}{612.} & \multirow{5}{*}{$\begin{array}{l}\text { At this facility Clinical management } \\
\text { protocols guidelines }\end{array}$} & & Yes & No & \\
\hline & & EmOC & 1 & 2 & \\
\hline & & IMCI & 1 & 2 & \\
\hline & & Infection prevention & 1 & 2 & \\
\hline & & Family planning & 1 & 2 & \\
\hline \multicolumn{6}{|c|}{ Other issues } \\
\hline 613. & $\begin{array}{l}\text { Is there any Hospital Management } \\
\text { Committee in this facility? }\end{array}$ & 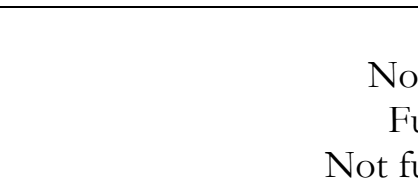 & $\begin{array}{l}\text { Formed } \\
\text { formed } \\
\text { actional } \\
\text { actional }\end{array}$ & $\begin{array}{l}\text { A } \\
\text { B } \\
\text { C } \\
\text { D }\end{array}$ & \\
\hline 614. & $\begin{array}{l}\text { Is there any Hospital Action Plan } \\
\text { (HAP) conducted in this facility? }\end{array}$ & $\begin{array}{r}\mathrm{Cc} \\
\text { Not cc } \\
\text { Report }\end{array}$ & $\begin{array}{l}\text { aducted } \\
\text { aducted } \\
\text { vailable }\end{array}$ & $\begin{array}{l}1 \\
2 \\
3\end{array}$ & \\
\hline
\end{tabular}




\begin{tabular}{|c|c|c|c|c|c|}
\hline NO & QUESTION/OBSERVATION & \multicolumn{2}{|l|}{ RESPONSE } & CODE & SKIP \\
\hline 615. & Is there any EmOC team in this facility? & \multicolumn{2}{|r|}{$\begin{array}{r}\text { Formed } \\
\text { Not formed }\end{array}$} & $\begin{array}{l}1 \\
2\end{array}$ & \\
\hline 616. & $\begin{array}{l}\text { Does EmOC review meeting held } \\
\text { regularly, held irregularly or not at all? }\end{array}$ & \multicolumn{2}{|c|}{$\begin{array}{r}\text { Held regularly (see minutes) } \\
\text { Held irregularly } \\
\text { Not at all }\end{array}$} & $\begin{array}{l}1 \\
2 \\
3\end{array}$ & \\
\hline 617. & $\begin{array}{l}\text { Is the Death Review Committee } \\
\text { functioning? }\end{array}$ & \multicolumn{2}{|r|}{$\begin{array}{l}\text { Yes } \\
\text { No }\end{array}$} & $\begin{array}{l}1 \\
2\end{array}$ & \\
\hline \multicolumn{2}{|c|}{$\begin{array}{l}\text { Quality of care } \\
\text { [FOR EACH ITEM, CIRCLE 'Y' FOR 'YES' OR 'N' FOR } \\
\text { 'NO' AS APPROPRIATE] }\end{array}$} & \multicolumn{2}{|c|}{ Available/Maintained } & \multicolumn{2}{|l|}{ Remarks } \\
\hline \multirow[t]{9}{*}{618.} & $\begin{array}{l}\text { Standard protocol for Infection } \\
\text { prevention }\end{array}$ & & & & \\
\hline & $\begin{array}{l}\text { a) Client's rights on infection } \\
\text { prevention }\end{array}$ & 1 & 2 & & \\
\hline & b) Infection prevention & 1 & 2 & & \\
\hline & Hand wash and wearing gloves & 1 & 2 & & \\
\hline & d) Instrument processing & 1 & 2 & & \\
\hline & e) Waste management & 1 & 2 & & \\
\hline & $\begin{array}{l}\text { f) Infection prevention in obstetrical } \\
\text { care }\end{array}$ & 1 & 2 & & \\
\hline & g) Infection prevention in OT & 1 & 2 & & \\
\hline & h) Initiatives to prevent infection & 1 & 2 & & \\
\hline 619. & Standard protocol for Family planning & & & & \\
\hline
\end{tabular}

**END** 


\section{Annexure 2: Physical Infrastructure Data}

\section{Gaibandha District}

\begin{tabular}{|c|c|c|c|c|}
\hline \multirow[t]{2}{*}{ Category } & \multicolumn{4}{|l|}{ Availability } \\
\hline & District Hospital, Gaibandha & Sundargonj UHC & Saghata UHC & Fulchari UHC \\
\hline Number of total beds & 100 & 31 & 31 & 31 \\
\hline Number of female beds & 65 & 12 & 12 & 10 \\
\hline Number of neo-natal beds & 10 & 0 & 2 & 5 \\
\hline Generator facility & Not functional & Not Available & Not Available & Not functional \\
\hline Communication facility & $\begin{array}{l}\text { Land Phone, Mobile Phone, } \\
\text { Computer (Available but not in } \\
\text { function) }\end{array}$ & $\begin{array}{l}\text { Land Phone, Mobile } \\
\text { Phone, Computer, } \\
\text { Internet Connection, } \\
\text { Computer based MIS } \\
\text { data }\end{array}$ & $\begin{array}{lr}\text { Mobile } & \text { Phone, } \\
\text { Computer, } & \text { Internet } \\
\text { Connection, } & \text { Computer } \\
\text { based MIS data } & \end{array}$ & $\begin{array}{l}\text { Land Phone, Mobile } \\
\text { Phone, Computer, } \\
\text { Internet Connection, } \\
\text { Computer based MIS } \\
\text { data }\end{array}$ \\
\hline Number of Labor room & 01 & 01 & 01 & 01 \\
\hline Number of Labor beds & 05 & 03 & - & 02 \\
\hline Infection management system & $\begin{array}{l}\text { - Labor Room } \\
\text { - Separate waste bin for liquids/ } \\
\text { solid/ syringe/ sharp. } \\
\text {-All labor instruments autoclaved } \\
\text { properly } \\
\text { - OT Room } \\
\text { - Separate waste bin for } \\
\text { liquids/solid/syringe/ sharp } \\
\text { - All labor instruments } \\
\text { autoclaved properly } \\
\end{array}$ & $\begin{array}{l}\text { - Labor Room } \\
\text { - } \quad \text { All waste in one } \\
\text { place } \\
\text { - OT Room } \\
\text {-All labor instruments } \\
\text { autoclaved properly }\end{array}$ & $\begin{array}{ll}\text { - } & \text { Labor Room } \\
\text { - } & \text { All waste in one } \\
& \text { place }\end{array}$ & $\begin{array}{l}\text { - Labor Room } \\
\text { - All waste in one } \\
\text { place }\end{array}$ \\
\hline Ambulance & Available & Available & Available & Available \\
\hline Availability of transport over phone & Available & Unavailable & Available & Available \\
\hline Payment for transport & Tk. $10 / \mathrm{km}$ & Tk. $10 / \mathrm{km}$ & Tk. $6 / \mathrm{km}$ & Tk. 8/ km. \\
\hline 24 hours and 7 days service facility & Not Available & $\begin{array}{l}\text { An Anesthesiologist on } \\
\text { duty }\end{array}$ & Not Available & Not Available \\
\hline
\end{tabular}




\section{Kurigram District}

\begin{tabular}{|c|c|c|c|c|}
\hline \multirow[t]{2}{*}{ Category } & \multicolumn{4}{|l|}{ Availability } \\
\hline & District Hospital, Kurirgam & Nageswari UHC & Bhurungamari UHC & Chilmary UHC \\
\hline Number of total beds & 100 & 31 & 31 & 50 \\
\hline Number of female beds & 35 & 14 & 15 & 16 \\
\hline Number of neo-natal beds & 12 & 02 & 0 & 0 \\
\hline Generator facility & Available and Functional & Available but not Functional & $\begin{array}{l}\text { Available bur not } \\
\text { Functional }\end{array}$ & $\begin{array}{l}\text { Available but not } \\
\text { Functional }\end{array}$ \\
\hline Communication facility & $\begin{array}{l}\text { Land Phone, Mobile Phone, } \\
\text { Computer, Internet connection, } \\
\text { Computer based MIS data }\end{array}$ & 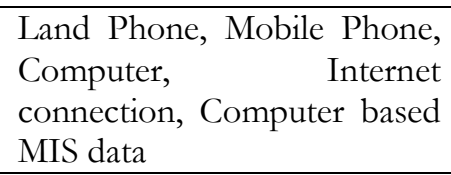 & $\begin{array}{l}\text { Land Phone, Mobile } \\
\text { Phone, Computer }\end{array}$ & $\begin{array}{l}\text { Land Phone, Mobile Phone, } \\
\text { Computer, } \\
\text { connection }\end{array}$ \\
\hline Number of Labor room & 1 & 1 & Not Functional & 1 \\
\hline Number of Labor beds & 2 & 2 & $\begin{array}{l}\text { - Operation Theater } \\
\text { - Unavailable } \\
\text { - Labor Room } \\
\text { - Unavailable }\end{array}$ & 1 \\
\hline $\begin{array}{l}\text { Infection management } \\
\text { system }\end{array}$ & $\begin{array}{l}\text { - Operation Theater } \\
\text { - All labor instruments autoclaved } \\
\text { properly and separate waste bin } \\
\text { for liquids/solid/syringe/sharp } \\
\text { - Labor Room } \\
\text { - All labor instruments autoclaved } \\
\text { properly but not separate waste } \\
\text { bin }\end{array}$ & $\begin{array}{l}\text { - OT } \\
\text { - All labor instruments } \\
\text { autoclaved properly but } \\
\text { not separate waste bin } \\
\text { - Labor Room } \\
\text { - All labor instruments } \\
\text { autoclaved properly but } \\
\text { not separate waste bin }\end{array}$ & Available & $\begin{array}{l}\text { - Operation Theater } \\
\text { - Unavailable } \\
\text { - Labor Room } \\
\text { - All waste in one bin }\end{array}$ \\
\hline Ambulance & Available & Available & Available & Unavailable \\
\hline $\begin{array}{l}\text { Availability of transport } \\
\text { over phone }\end{array}$ & Available & Available & Yes $(10 \mathrm{Tk} / \mathrm{km})$ & - \\
\hline Payment for transport & Yes $(10 / \mathrm{km})$ & Yes $(6 / \mathrm{km})$ & Unavailable & Yes $(10 / \mathrm{km})$ \\
\hline $\begin{array}{l}24 \text { hours and } 7 \text { days service } \\
\text { facility }\end{array}$ & $\begin{array}{l}\text { An Obstetrician, an Gynecologist, } \\
\text { and an Anesthesiologist and blood } \\
\text { transfusion with screening is } \\
\text { available }\end{array}$ & $\begin{array}{l}\text { An Obstetrician, an } \\
\text { Gynecologist, and an } \\
\text { Anesthesiologist is available }\end{array}$ & & Unavailable \\
\hline
\end{tabular}




\section{Jamalpur District}

\begin{tabular}{|c|c|c|c|c|}
\hline \multirow[t]{2}{*}{ Category } & \multicolumn{4}{|l|}{ Availability } \\
\hline & District Hospital, Jamalpur & Islampur UHC & Melandha UHC & Bakshigonj UHC \\
\hline Number of total beds & 250 & 31 & 31 & 31 \\
\hline Number of female beds & 48 & 10 & 12 & 12 \\
\hline Number of neo-natal beds & 10 & 0 & 0 & 0 \\
\hline Generator facility & Available in OT only & Not Available & Not Available & Not Available \\
\hline Communication facility & $\begin{array}{l}\text { Land Phone, Mobile Phone, } \\
\text { Computer, Internet Connection, } \\
\text { Computer based MIS Data }\end{array}$ & $\begin{array}{l}\text { Mobile Phone, Computer, } \\
\text { Internet Connection }\end{array}$ & $\begin{array}{l}\text { Land Phone, Mobile } \\
\text { Phone, Computer, Internet } \\
\text { Connection }\end{array}$ & $\begin{array}{l}\text { Land Phone, Mobile Phone, } \\
\text { Computer, Internet } \\
\text { Connection }\end{array}$ \\
\hline Number of Labor room & 01 & 01 & 01 & 01 \\
\hline Number of Labor beds & 02 & 04 & 02 & 06 \\
\hline $\begin{array}{l}\text { Infection management } \\
\text { system }\end{array}$ & $\begin{array}{l}\text { - Labor Room } \\
\text { - Separate waste bin for } \\
\text { liquids/ solid/ syringe/ } \\
\text { sharp. All labor instruments } \\
\text { autoclaved properly } \\
\text { - OT Room } \\
\text { - All labor instruments } \\
\text { autoclaved properly }\end{array}$ & $\begin{array}{ll}\text { - } & \text { Labor Room } \\
\text { - Two separate bin for } \\
\text { waste disposal. }\end{array}$ & $\begin{array}{l}\text { - Labor Room } \\
\text { - All labor instruments } \\
\text { autoclaved properly }\end{array}$ & $\begin{array}{l}\text { - Labor Room } \\
\text { - Separate waste bin for } \\
\text { liquids/solid/syringe/ } \\
\text { sharp. }\end{array}$ \\
\hline Ambulance & Available & Available & Available & Available \\
\hline $\begin{array}{l}\text { Availability of transport } \\
\text { over phone }\end{array}$ & Available & Available & Available & Available \\
\hline Payment for transport & Tk. 500 per call & Tk. 660 per call & Tk. $6 / \mathrm{km}$ & Tk. $10 / \mathrm{km}$ \\
\hline $\begin{array}{l}24 \text { hours and } 7 \text { days service } \\
\text { facility }\end{array}$ & $\begin{array}{l}\text { An Obstetrician, Gynecologist, } \\
\begin{array}{l}\text { Anesthesiologist and Blood } \\
\text { transfusion with screening is } \\
\text { available }\end{array}\end{array}$ & Not Available & $\begin{array}{l}\text { An Obstetrician and } \\
\text { Gynecologist on duty }\end{array}$ & Not Available \\
\hline
\end{tabular}




\section{Thakurgaon District}

\begin{tabular}{|c|c|c|c|c|}
\hline \multirow[t]{2}{*}{ Category } & \multicolumn{4}{|l|}{ Availability } \\
\hline & District Hospital, Thakurgaon & Baliadangi UHC & Pirganj UHC & Ranishonkoil UHC \\
\hline Number of total beds & 100 & 50 & 31 & 50 \\
\hline Number of female beds & 25 & 34 & 15 & 26 \\
\hline Number of neo-natal beds & 18 & 5 & 4 & 0 \\
\hline Generator facility & Available but not functional & Unavailable & Available bur only for OT & Available and functional \\
\hline Communication facility & $\begin{array}{l}\text { Land Phone, Mobile Phone, } \\
\text { Computer, Internet connection, } \\
\text { Computer based MIS data }\end{array}$ & $\begin{array}{l}\text { Land Phone, Mobile Phone, } \\
\text { Computer not functioning }\end{array}$ & $\begin{array}{l}\text { Land Phone, Mobile } \\
\text { Phone, Computer }\end{array}$ & $\begin{array}{l}\text { Land Phone, Computer, } \\
\text { Internet connection }\end{array}$ \\
\hline Number of Labor room & 1 & 1 & 1 & 1 \\
\hline Number of Labor beds & 26 & 3 & 5 & 2 \\
\hline $\begin{array}{l}\text { Infection management } \\
\text { system }\end{array}$ & $\begin{array}{l}\text { - OT } \\
\text { - All instruments autoclaved } \\
\text { properly and also separate } \\
\text { waste bin for different waste } \\
\text { - Labor Room } \\
\text { - All labor instruments } \\
\text { autoclaved properly and also } \\
\text { separate waste bin for } \\
\text { different waste }\end{array}$ & $\begin{array}{ll}\text { - } & \text { OT } \\
- & \text { All instruments } \\
& \text { autoclaved properly } \\
- & \\
- & \text { Labor Room } \\
- & \text { All labor instruments } \\
& \text { autoclaved properly }\end{array}$ & $\begin{array}{ll}\text { - } & \text { OT } \\
\text { - } & \text { All instruments } \\
& \text { autoclaved properly } \\
\text { - } & \text { Labor Room } \\
\text { - } & \text { All labor instruments } \\
& \text { autoclaved properly }\end{array}$ & $\begin{array}{ll}\text { - OT } \\
\text { - Not functional } \\
\text { - Labor Room } \\
\text { - Separate waste bin for } \\
\text { different waste }\end{array}$ \\
\hline Ambulance & $\begin{array}{l}\begin{array}{l}\text { Available (among } 5 \text { only } 1 \text { in } \\
\text { action) }\end{array} \\
\end{array}$ & Unavailable & Available & Available \\
\hline $\begin{array}{l}\text { Availability of transport } \\
\text { over phone }\end{array}$ & Available but not always function & - & Available & Available \\
\hline Payment for transport & Yes $(10 / \mathrm{km})$ & - & Yes $(10 \mathrm{Tk} / \mathrm{km})$ & Yes $(10 \mathrm{Tk} / \mathrm{km})$ \\
\hline $\begin{array}{l}24 \text { hours and } 7 \text { days service } \\
\text { facility }\end{array}$ & $\begin{array}{l}\text { An Obstetrician, an Gynecologist, } \\
\text { and an Anesthesiologist is available }\end{array}$ & $\begin{array}{l}\text { An Obstetrician, an } \\
\text { Gynecologist, and an } \\
\text { Anesthesiologist is available }\end{array}$ & Unavailable & Unavailable \\
\hline
\end{tabular}




\section{Annexure 3: Health Human Resources Data}

\section{District Hospital}

\begin{tabular}{|c|c|c|c|c|c|c|c|c|}
\hline \multirow[t]{2}{*}{ Position } & \multicolumn{2}{|c|}{$\begin{array}{l}\text { District Hospital, } \\
\text { Gaibandha }\end{array}$} & \multicolumn{2}{|c|}{$\begin{array}{c}\text { District Hospital, } \\
\text { Kurigram }\end{array}$} & \multicolumn{2}{|c|}{ District Hospital, Jamalpur } & \multicolumn{2}{|c|}{$\begin{array}{c}\text { District Hospital, } \\
\text { Thakurgaon }\end{array}$} \\
\hline & $\begin{array}{l}\text { Sanctioned } \\
\text { Post }\end{array}$ & $\begin{array}{c}\text { Available } \\
\text { Post }\end{array}$ & $\begin{array}{c}\text { Sanctioned } \\
\text { Post }\end{array}$ & $\begin{array}{l}\text { Available } \\
\text { Post }\end{array}$ & $\begin{array}{c}\text { Sanctioned } \\
\text { Post }\end{array}$ & $\begin{array}{c}\text { Available } \\
\text { Post }\end{array}$ & $\begin{array}{l}\text { Sanctioned } \\
\text { Post }\end{array}$ & $\begin{array}{c}\text { Available } \\
\text { Post }\end{array}$ \\
\hline \multicolumn{9}{|l|}{ Managers: } \\
\hline Civil Surgeon & 1 & 1 & 1 & 1 & 1 & 1 & 1 & 1 \\
\hline DD Family & 1 & 1 & 1 & 1 & 1 & 1 & 1 & 0 \\
\hline \multicolumn{9}{|l|}{ Consultants: } \\
\hline Pediatrics & 1 & 1 & 1 & 0 & 1 & 0 & 1 & 0 \\
\hline Gyn and obs & 2 & 0 & 2 & 1 & 2 & 1 & 2 & 1 \\
\hline Anesthesia & 1 & 0 & 1 & 0 & 1 & 1 & 1 & 1 \\
\hline Medical Officer & 7 & 5 & 5 & 4 & 7 & 7 & 4 & 0 \\
\hline $\begin{array}{l}\text { Emergency } \\
\text { Medical Officer }\end{array}$ & 3 & 2 & 1 & 1 & 4 & 3 & 3 & 3 \\
\hline $\begin{array}{l}\text { Resident } \\
\text { Medical Officer }\end{array}$ & 1 & 1 & 3 & 3 & 1 & 1 & 1 & 1 \\
\hline $\begin{array}{l}\text { Senior Staff } \\
\text { Nurse }\end{array}$ & 23 & 20 & 34 & 32 & 37 & 36 & 27 & 27 \\
\hline Assistant Nurse & 5 & 4 & 2 & 2 & 6 & 6 & 5 & 5 \\
\hline
\end{tabular}




\section{Comprehensive Emergency Obstetric and Neonatal Care UHC}

\begin{tabular}{|c|c|c|c|c|c|c|c|c|}
\hline \multirow[t]{2}{*}{ Position } & \multicolumn{2}{|c|}{ Sundargonj UHC } & \multicolumn{2}{|c|}{ Nageswari UHC } & \multicolumn{2}{|c|}{ Islampur UHC } & \multicolumn{2}{|c|}{ Baliadangi UHC } \\
\hline & $\begin{array}{c}\text { Sanctioned } \\
\text { Post }\end{array}$ & $\begin{array}{c}\text { Available } \\
\text { Post }\end{array}$ & $\begin{array}{c}\text { Sanctioned } \\
\text { Post }\end{array}$ & $\begin{array}{c}\text { Available } \\
\text { Post }\end{array}$ & $\begin{array}{l}\text { Sanctioned } \\
\text { Post }\end{array}$ & $\begin{array}{c}\text { Available } \\
\text { Post }\end{array}$ & $\begin{array}{l}\text { Sanctioned } \\
\text { Post }\end{array}$ & $\begin{array}{c}\text { Available } \\
\text { Post }\end{array}$ \\
\hline \multicolumn{9}{|l|}{ Managers: } \\
\hline UHFPO & 1 & 1 & 1 & 1 & 1 & 1 & 1 & 1 \\
\hline UFPO & 1 & 1 & 1 & 1 & 1 & 1 & 1 & 0 \\
\hline \multicolumn{9}{|l|}{ Consultants: } \\
\hline Pediatrics & 1 & 0 & 1 & 1 & 1 & 1 & 1 & 0 \\
\hline Gyn and obs & 1 & 1 & 1 & 1 & 1 & 1 & 1 & 0 \\
\hline Anesthesia & 1 & 1 & 1 & 0 & 1 & 1 & 1 & 1 \\
\hline Medical Officer & 2 & 0 & 4 & 4 & 4 & 4 & 2 & 2 \\
\hline MO (MCH-FP) & 1 & 1 & 1 & 0 & 1 & 1 & 1 & 0 \\
\hline $\begin{array}{l}\text { Resident } \\
\text { Medical Officer }\end{array}$ & 1 & 0 & 1 & 1 & 1 & 0 & 1 & 1 \\
\hline $\begin{array}{l}\text { Senior Staff } \\
\text { Nurse }\end{array}$ & 9 & 9 & 13 & 13 & 11 & 10 & 15 & 7 \\
\hline Assistant Nurse & 1 & 0 & 1 & 0 & 1 & 0 & 1 & 0 \\
\hline
\end{tabular}


Basic Emergency Obstetric and Neonatal Care UHC

\begin{tabular}{|c|c|c|c|c|c|c|c|c|}
\hline \multirow[t]{2}{*}{ Position } & \multicolumn{2}{|c|}{ Fulchari UHC } & \multicolumn{2}{|c|}{ Saghata UHC } & \multicolumn{2}{|c|}{ Bhurungamari UHC } & \multicolumn{2}{|c|}{ Chilmary UHC } \\
\hline & $\begin{array}{l}\text { Sanctioned } \\
\text { Post }\end{array}$ & $\begin{array}{c}\text { Available } \\
\text { Post }\end{array}$ & $\begin{array}{c}\text { Sanctioned } \\
\text { Post }\end{array}$ & $\begin{array}{c}\text { Available } \\
\text { Post }\end{array}$ & $\begin{array}{c}\text { Sanctioned } \\
\text { Post }\end{array}$ & $\begin{array}{c}\text { Available } \\
\text { Post }\end{array}$ & $\begin{array}{c}\text { Sanctioned } \\
\text { Post }\end{array}$ & $\begin{array}{c}\text { Available } \\
\text { Post }\end{array}$ \\
\hline \multicolumn{9}{|l|}{ Managers: } \\
\hline UHFPO & 1 & 1 & 1 & 1 & 1 & 1 & 1 & 1 \\
\hline UFPO & 1 & 0 & 1 & 1 & 1 & 1 & 1 & 1 \\
\hline \multicolumn{9}{|l|}{ Consultants: } \\
\hline Pediatrics & 1 & 0 & 1 & 0 & 1 & 0 & 1 & 1 \\
\hline Gyn and obs & 1 & 0 & 1 & 0 & 1 & 1 & 1 & 0 \\
\hline Anesthesia & 1 & 0 & 1 & 0 & 1 & 1 & 1 & 0 \\
\hline Medical Officer & 2 & 2 & 2 & 0 & 2 & 2 & 6 & 1 \\
\hline MO (MCH-FP) & 1 & 0 & 1 & 0 & 1 & 0 & 1 & 1 \\
\hline $\begin{array}{l}\text { Resident } \\
\text { Medical Officer }\end{array}$ & 1 & 0 & 1 & 0 & 1 & 1 & 1 & 0 \\
\hline $\begin{array}{l}\text { Senior Staff } \\
\text { Nurse }\end{array}$ & 9 & 9 & 9 & 9 & 9 & 8 & 14 & 6 \\
\hline Assistant Nurse & 1 & 0 & 1 & 0 & 1 & 0 & 1 & 1 \\
\hline
\end{tabular}


Basic Emergency Obstetric and Neonatal Care UHC

\begin{tabular}{|c|c|c|c|c|c|c|c|c|}
\hline \multirow[t]{2}{*}{ Position } & \multicolumn{2}{|c|}{ Melandha UHC } & \multicolumn{2}{|c|}{ Bakshiganj UHC } & \multicolumn{2}{|c|}{ Pirganj UHC } & \multicolumn{2}{|c|}{ Ranishonkoil UHC } \\
\hline & $\begin{array}{c}\text { Sanctioned } \\
\text { Post }\end{array}$ & $\begin{array}{l}\text { Available } \\
\text { Post }\end{array}$ & $\begin{array}{c}\text { Sanctioned } \\
\text { Post }\end{array}$ & $\begin{array}{c}\text { Available } \\
\text { Post }\end{array}$ & $\begin{array}{c}\text { Sanctioned } \\
\text { Post }\end{array}$ & $\begin{array}{c}\text { Available } \\
\text { Post }\end{array}$ & $\begin{array}{c}\text { Sanctioned } \\
\text { Post }\end{array}$ & $\begin{array}{c}\text { Available } \\
\text { Post }\end{array}$ \\
\hline \multicolumn{9}{|l|}{ Managers: } \\
\hline UHFPO & 1 & 1 & 1 & 1 & 1 & 1 & 1 & 0 \\
\hline UFPO & 1 & 0 & 1 & 1 & 1 & 0 & 1 & 1 \\
\hline \multicolumn{9}{|l|}{ Consultants: } \\
\hline Pediatrics & 1 & 1 & 1 & 0 & 0 & - & 1 & 0 \\
\hline Gyn and obs & 1 & 1 & 1 & 0 & 1 & 0 & 1 & 0 \\
\hline Anesthesia & 1 & 1 & 1 & 1 & 1 & 1 & 1 & 0 \\
\hline Medical Officer & 4 & 4 & 2 & 1 & 4 & 2 & 3 & 1 \\
\hline MO (MCH-FP) & 1 & 1 & 1 & 0 & 1 & 1 & 1 & 1 \\
\hline $\begin{array}{l}\text { Resident } \\
\text { Medical Officer }\end{array}$ & 1 & 1 & 1 & 1 & 1 & 0 & 1 & 0 \\
\hline $\begin{array}{l}\text { Senior Staff } \\
\text { Nurse } \\
\end{array}$ & 14 & 10 & 9 & 6 & 9 & 8 & 14 & 4 \\
\hline Assistant Nurse & 1 & 1 & 1 & 0 & 1 & 1 & 1 & 1 \\
\hline
\end{tabular}




\section{Annexure 4: Equipment and Supplies Data}

\section{Gaibandha District}

\begin{tabular}{|c|c|c|c|c|c|c|c|c|}
\hline \multirow[t]{2}{*}{ Category } & \multicolumn{2}{|c|}{$\begin{array}{c}\text { District Hospital, } \\
\text { Gaibandha }\end{array}$} & \multicolumn{2}{|c|}{ Sundargonj UHC } & \multicolumn{2}{|c|}{ Fulchari UHC } & \multicolumn{2}{|c|}{ Saghata UHC } \\
\hline & Availability & Usability & Availability & Usability & Availability & Usability & Availability & Usability \\
\hline Anesthesia Machine & Available & Usable & Available & Non-usable & Available & Non-usable & Unavailable & - \\
\hline Oxygen Cylinder & Available & Usable & Available & Usable & Available & Usable & Available & Usable \\
\hline Light emergency & Available & Usable & Available & Usable & Available & Usable & Available & Usable \\
\hline Vacuum extractor & Unavailable & - & Available & Usable & Unavailable & - & Unavailable & - \\
\hline Functioning Forceps & Available & Usable & Available & Usable & Unavailable & - & Unavailable & - \\
\hline Delivery set & Available & Usable & Available & Usable & Unavailable & - & Unavailable & Usable \\
\hline Sucker machine & Available & Usable & Available & Usable & Available & Usable & Available & Usable \\
\hline Ambu bag & Available & Usable & Available & Usable & Available & Usable & Available & Usable \\
\hline Neo-natal resuscitator & Unavailable & - & Unavailable & - & Unavailable & - & Unavailable & - \\
\hline Nebulise solution & Unavailable & - & Unavailable & - & Unavailable & - & Available & $\begin{array}{l}\text { Non- } \\
\text { usable }\end{array}$ \\
\hline Weight Machine & Available & Usable & - & - & Available & Usable & Available & Usable \\
\hline $\begin{array}{l}\text { Blood grouping and } \\
\text { cross matching reagents }\end{array}$ & Available & Usable & Available & Non-usable & Unavailable & - & Unavailable & - \\
\hline Blood bag & Unavailable & - & Unavailable & - & Unavailable & - & Unavailable & - \\
\hline $\begin{array}{l}\text { Doctor's gown, musk, } \\
\text { and cap }\end{array}$ & Available & Usable & Available & Usable & Available & Non-usable & Unavailable & - \\
\hline Gloves & Unavailable & - & Available & Usable & Available & Non-usable & Available & Usable \\
\hline
\end{tabular}




\section{Kurigram District}

\begin{tabular}{|c|c|c|c|c|c|c|c|c|}
\hline \multirow[t]{2}{*}{ Category } & \multicolumn{2}{|c|}{$\begin{array}{c}\text { District Hospital, } \\
\text { Kurigram }\end{array}$} & \multicolumn{2}{|c|}{ Nageswari UHC } & \multicolumn{2}{|c|}{ Bhurungamari UHC } & \multicolumn{2}{|c|}{ Chilmary UHC } \\
\hline & Availability & Usability & Availability & Usability & Availability & Usability & Availability & Usability \\
\hline Anesthesia Machine & Available & Usable & Available & Usable & Unavailable & - & Unavailable & - \\
\hline Weight Machine & Available & Usable & Available & Usable & Available & Usable & Available & Usable \\
\hline Oxygen Cylinder & Available & Usable & Available & Usable & Available & Usable & Available & Usable \\
\hline Light emergency & Available & Usable & Available & Usable & Unavailable & - & Unavailable & - \\
\hline Vacuum extractor & Unavailable & - & Available & Usable & Unavailable & - & Unavailable & - \\
\hline Functioning Forceps & Unavailable & - & Available & Usable & Unavailable & - & Unavailable & - \\
\hline Delivery set & Available & Non-usable & Available & Usable & Unavailable & - & Available & - \\
\hline Sucker machine & Available & Usable & Available & Usable & Unavailable & - & Available & - \\
\hline Ambu bag & Available & Usable & Available & Usable & Available & Usable & Available & Usable \\
\hline Neo-natal resuscitator & Unavailable & - & Available & Usable & Available & Usable & Unavailable & - \\
\hline Nebulise solution & Available & Usable & Unavailable & - & Available & Usable & Unavailable & - \\
\hline $\begin{array}{l}\text { Blood grouping and } \\
\text { cross matching reagents }\end{array}$ & Available & Usable & Available & $\begin{array}{l}\text { Non- } \\
\text { usable }\end{array}$ & Available & Usable & Available & $\begin{array}{l}\text { Non- } \\
\text { usable }\end{array}$ \\
\hline Blood bag & Available & Usable & Unavailable & - & Unavailable & - & Available & $\begin{array}{l}\text { Non- } \\
\text { usable }\end{array}$ \\
\hline $\begin{array}{l}\text { Doctor's gown, musk, } \\
\text { and cap }\end{array}$ & Available & Usable & Available & Usable & Unavailable & - & Unavailable & - \\
\hline Gloves & Available & Usable & Available & Usable & Available & Usable & Available & Usable \\
\hline
\end{tabular}




\section{Jamalpur District}

\begin{tabular}{|c|c|c|c|c|c|c|c|c|}
\hline \multirow[t]{2}{*}{ Category } & \multicolumn{2}{|c|}{$\begin{array}{c}\text { District Hospital, } \\
\text { Jamalpur }\end{array}$} & \multicolumn{2}{|c|}{ Islampur UHC } & \multicolumn{2}{|c|}{ Melandha UHC } & \multicolumn{2}{|c|}{ Bakshiganj UHC } \\
\hline & Availability & Usability & Availability & Usability & Availability & Usability & Availability & Usability \\
\hline Anesthesia Machine & Available & Usable & Unavailable & - & Unavailable & - & Unavailable & - \\
\hline Oxygen Cylinder & Available & Usable & Available & Usable & Available & Usable & Available & Usable \\
\hline Light emergency & Unavailable & - & Available & Usable & Available & Usable & Unavailable & - \\
\hline Vacuum extractor & Available & Usable & Available & Usable & Available & Usable & Unavailable & - \\
\hline Functioning Forceps & Unavailable & - & Available & Usable & Available & Usable & Available & $\begin{array}{l}\text { Non- } \\
\text { usable }\end{array}$ \\
\hline Delivery set & Available & Usable & Available & Usable & Available & Usable & Available & Usable \\
\hline Sucker machine & Available & Usable & Available & Usable & Available & Usable & Available & Usable \\
\hline Ambu bag & Available & Usable & Available & Usable & Available & Usable & Available & Usable \\
\hline Neo-natal resuscitator & Available & Usable & Unavailable & - & Available & Usable & Unavailable & - \\
\hline Nebulise solution & Unavailable & - & Available & Usable & Available & Usable & Available & Usable \\
\hline Weight Machine & Available & Usable & Available & Usable & & & Available & Usable \\
\hline $\begin{array}{l}\text { Blood grouping and } \\
\text { cross matching reagents }\end{array}$ & Unavailable & - & Available & Usable & Unavailable & - & Unavailable & - \\
\hline Blood bag & Unavailable & - & Available & Usable & Available & Usable & Unavailable & - \\
\hline $\begin{array}{l}\text { Doctor's gown, musk, } \\
\text { and cap }\end{array}$ & Available & Usable & Available & Usable & Unavailable & - & Unavailable & - \\
\hline Gloves & Unavailable & - & Available & Usable & Available & Usable & Available & Usable \\
\hline
\end{tabular}




\section{Thakurgaon District}

\begin{tabular}{|c|c|c|c|c|c|c|c|c|}
\hline \multirow[t]{2}{*}{ Category } & \multicolumn{2}{|c|}{$\begin{array}{c}\text { District Hospital, } \\
\text { Thakurgaon }\end{array}$} & \multicolumn{2}{|c|}{ Baliadangi UHC } & \multicolumn{2}{|c|}{ Pirganj UHC } & \multicolumn{2}{|c|}{ Ranishankoil UHC } \\
\hline & Availability & Usability & Availability & Usability & Availability & Usability & Availability & Usability \\
\hline Anesthesia Machine & Available & Usable & Available & Usable & Available & Usable & Available & Non-usable \\
\hline Weight Machine & Available & Usable & Available & Usable & Available & Usable & Available & Usable \\
\hline Oxygen Cylinder & Available & Usable & Available & Usable & Available & Usable & Available & Non-usable \\
\hline Light emergency & Available & Usable & Available & Usable & Available & Usable & Available & Usable \\
\hline Vacuum extractor & Available & Usable & Available & Usable & Unavailable & - & Available & Usable \\
\hline Functioning Forceps & Available & Usable & Available & Usable & Available & Usable & Unavailable & - \\
\hline Delivery set & Available & Usable & Available & Usable & Available & Usable & Available & Usable \\
\hline Sucker machine & Available & Usable & Available & Usable & Available & Usable & Available & Usable \\
\hline Ambu bag & Available & Usable & Available & Usable & Available & Usable & Available & Usable \\
\hline Neo-natal resuscitator & Available & Usable & Available & Usable & Available & Usable & Unavailable & - \\
\hline Nebulise solution & Unavailable & - & Available & Non-usable & Available & Usable & Available & Usable \\
\hline $\begin{array}{l}\text { Blood grouping and } \\
\text { cross matching reagents }\end{array}$ & Available & Usable & Available & Usable & Available & Usable & Unavailable & - \\
\hline Blood bag & Available & Usable & Available & Usable & Available & Usable & Unavailable & - \\
\hline $\begin{array}{l}\text { Doctor's gown, musk, } \\
\text { and cap }\end{array}$ & Available & Usable & Available & Usable & Available & Usable & Available & Usable \\
\hline Gloves & Available & Usable & Available & Usable & Available & Usable & Available & Usable \\
\hline
\end{tabular}




\section{(1) Population Council}

www.popcouncil.org

South \& East Asia - Bangladesh Office

House CES(B) 21, Road 118

Gulshan, Dhaka, Bangladesh

Phone : $8802-8821227,8826657$

Fax : $8802-8823127$

Email : info.bangladesh@popcouncilorg 